\title{
An Improved Fourier Series Method for the Free Vibration Analysis of the Three-Dimensional Coupled Beams
}

\author{
Runze Zhang, ${ }^{1}$ Yipeng Cao, ${ }^{1}$ Wenping Zhang, ${ }^{1}$ Hongbo $\mathrm{Li}^{2}$ and Xiangmei $\mathrm{Li}^{3}$ \\ ${ }^{1}$ College of Power and Energy Engineering, Harbin Engineering University, Harbin, China \\ ${ }^{2}$ Hudong-Zhonghua Shipbuilding (Group) CO., LTD., Shanghai, China \\ ${ }^{3}$ China Maritime Police Academy, Zhejiang, China \\ Correspondence should be addressed to Yipeng Cao; yipengcao06@163.com
}

Received 7 July 2016; Accepted 17 October 2016

Academic Editor: Brij N. Agrawal

Copyright (C) 2016 Runze Zhang et al. This is an open access article distributed under the Creative Commons Attribution License, which permits unrestricted use, distribution, and reproduction in any medium, provided the original work is properly cited.

\begin{abstract}
This paper presents a free vibration analysis of three-dimensional coupled beams with arbitrary coupling angle using an improved Fourier method. The displacement and rotation of the coupled beams are represented by the improved Fourier series which consisted of Fourier cosine series and closed-form auxiliary functions. The coupling and boundary conditions are accomplished by setting coupling and boundary springs and assigning corresponding stiffness values to the springs. Modal parameters are determined through the application of Rayleigh-Ritz procedure to the system energy formulation. The accuracy and convergence of the present method are demonstrated by finite element method (FEM) result. Investigation on vibration of the propulsion shafting structure shows the extensive applicability of present method. The studies on the vibration suppression devices are also reported.
\end{abstract}

\section{Introduction}

For the propeller running in the nonuniform wake fluid field, the longitudinal and lateral vibrations of the propulsion shafting will be stimulated. In the following, the shafting longitudinal and lateral vibration energy transfers from shafting to bearing pedestal, thereby to the structure which will cause structure underwater radiated noise. Therefore, it is necessary to find a method that can not only calculate the vibration characteristics of the propulsion shafting but also consider the shell structure in the following step.

There is a vast amount of information available on the longitudinal or lateral vibration of propulsion shafting. Zhang and Zhao [1, 2] obtained the longitudinal vibration modes of the propulsion shafting using onedimension elastic wave approach based on its continuous model. The coupled longitudinal-transverse dynamics of the marine propulsion shafting under primary and internal responses was investigated by Zou et al. [3]. The coupled longitudinal-transverse dynamic model is established by using the extended Hamilton principle and discretized by Galerkin method. Huang et al. [4] researched the coupled torsional-longitudinal vibration of the propulsion shafting.
The changes of displacement and rotation angle caused by coupled torsional-longitudinal vibration of the propulsion shafting are studied by the finite element method. Zhou et al. [5] applied the finite element method to calculate the ship propulsion shafting vibration responses under the propeller bearing forces. Li et al. [6] studied the dynamic and acoustic characteristics of the coupled propeller and shafting system by transfer matrix method. Kane and McGoldrick [7] studied the dynamic behavior of the propulsion shafting caused by longitudinal excitation. Pan et al. [8] used a series of mass spring damper system to simulate the propulsion shafting and performed experiment analysis, they simplified propeller as lumped mass, and the fluid load used the added mass to be simulated.

Among those papers, the shafting is assumed to be a uniform cross-section beam. A wide spectrum of techniques has been developed for the vibrations of beams. Some authors have investigated the dynamic analyses of multispan beams which used modern numerical methods such as the finite element method.

Bishop and Johnson [9] presented a modal receptance approach to the case single and coupled beam structure. 
Farag and Pan [10] applied the receptance approach technique to the dynamic response and power flower flow of the three-dimensional coupled beam structure. Lee [11] used the assumed mode method to research the transverse vibration of a Timoshenko beam which is acted on by accelerating mass. Wu and Hsu [12] studied free vibration analysis of simply supported beams carrying multiple point mass and spring-mass system. Li [13-16] proposed an improved Fourier series method to establish the multispan beam model with the elastic support and calculated the natural characteristics and dynamic response under moving load. An analytical solution consisting of the expansion of the displacement function into a Fourier series, the calculation of the kinetic energy and the elastic strain energy, and then solving the Lagrange equation is presented by Heidebrecht in [17].

The two-dimensional coupled beams model is used in the shafting vibration calculation. However, the effect of the torsional force caused by the propeller can not be expressed well. Therefore, in order to study the characteristic of shafting vibration with the numerical method better, the threedimensional coupled beams are selected as the research object in this paper. The displacements and rotation components of the coupled beams are expressed as an improved Fourier series in which the closed-form auxiliary functions introduced to remove any potential discontinuities and ensure the convergence of the solution. All the coefficients will be solved directly from the Rayleigh-Ritz procedure. The convergence and accuracy of the present method are verified by numerical examples.

\section{Theoretical Formulations}

2.1. Theoretical Model. The three-dimensional coupled beams model is presented in Figure 1, together with the global and local coordinates employed in this paper. This model indicates ample information including general boundary condition, arbitrary coupling angles, and elastically coupled condition. In order to simulate the general boundary conditions and the elastically coupled condition, artificial spring technique is adopted here. Specifically, six sets of stiffness-like springs are used at the end of the beam with rectangular coordinates, including three sets of linear springs, respectively, along the $x-, y$-, $z$-directions, and three sets of rotational springs around the $x$-, $y$-, $z$-directions. The general boundary conditions can be achieved by varying the value of springs' stiffness. The springs are assigned very high stiffness values for a clamped edge or zero for a free boundary condition. Similarly, another six sets of springs are used to link the adjacent beams. For a rigid connection, the stiffness of all the springs can be assigned an infinite valve. Through assigning the springs at proper stiffness, the isolator can be readily achieved. The form of springs is shown in Table 1 . The counterclockwise is predefined as the positive direction of the coupling angle which is variable in the range from $-\pi$ to $\pi$. The angle $\left(\alpha_{i}\right)$ of each beam was obtained by the angle between the local and the global coordinate. The arbitrary coupling angle $\left(\theta_{i, j}\right)$ can be achieved by varying the value of the angle $\left(\alpha_{i}\right)$ of each beam.
2.2. Energy Functional of Coupled Beams Structure. The total energy function of the coupled beams is taken as the sum of the energy contributions from the beam components, coupling constraints, and boundary constraints. Thus, the Lagrangian energy function of the coupled structure can be expressed as

$$
L=\sum_{i=1}^{2} V_{i}-\sum_{i=1}^{2} T_{i}+\sum_{i=1}^{2} V_{i}^{B . C}+\sum_{i=1}^{2} \sum_{j=1}^{2}\left(1-\delta_{i j}\right) V_{i j}^{C} .
$$

$\delta_{i j}$ is the coefficient, and if $|i-j|=1, \delta_{i j}=0$; otherwise $\delta_{i j}=1$.

Also the strain energy and the kinetic energy for the coupled beams can be written as

$$
\begin{aligned}
V_{i} & =\frac{1}{2} \int_{0}^{l_{i}}\left[E _ { i } \left(S_{i}\left(\frac{\partial U_{i}}{\partial x}\right)^{2}+I_{i, z}\left(\frac{\partial^{2} W_{i, y}}{\partial x^{2}}\right)^{2}\right.\right. \\
& \left.\left.+I_{i, y}\left(\frac{\partial^{2} W_{i, z}}{\partial x^{2}}\right)^{2}\right)+\frac{1}{2} G_{i} I_{p}\left(\frac{\partial \Theta_{i}}{\partial x}\right)^{2}\right], \\
T_{i} & =\frac{1}{2} \int_{0}^{l_{i}}\left(\rho_{i} S_{i} \dot{U}_{i}^{2}+\rho_{i} S_{i} \dot{W}_{i, y}^{2}+\rho_{i} S_{i} \dot{W}_{i, z}^{2}+J_{i} \dot{\Theta}_{i}^{2}\right) d x .
\end{aligned}
$$

The potential energy stored in the boundary and coupling springs can be described as

$$
\begin{aligned}
V_{i}^{B . C} & =\frac{1}{2} \cdot\left(\mathbf{U}_{i}^{T} \mathbf{K}_{B . C}^{0} \mathbf{U}_{i}\right)_{x=0}+\frac{1}{2} \cdot\left(\mathbf{U}_{i}^{T} \mathbf{K}_{B . C}^{l_{i}} \mathbf{U}_{i}\right)_{x=l_{i}}, \\
V_{i j}^{C} & =\frac{1}{2} \cdot\left(\overline{\mathbf{U}}_{i}-\overline{\mathbf{U}}_{j}\right)^{T} \mathbf{K}_{c}^{i j}\left(\overline{\mathbf{U}}_{i}-\overline{\mathbf{U}}_{j}\right),
\end{aligned}
$$

where

$$
\begin{aligned}
& \mathbf{U}_{i}=\left[\begin{array}{llllll}
\mu_{i} & w_{i, y} & w_{i, z} & \theta_{i} & \frac{\partial w_{i, z}}{\partial x} & \frac{\partial w_{i, y}}{\partial x}
\end{array}\right]^{T} e^{j \omega t}, \\
& \mathbf{K}_{B . C}^{0}=\operatorname{diag}\left[\begin{array}{llllll}
k_{(i, 1)}^{x} & k_{(i, 1)}^{y} & k_{(i, 1)}^{z} & K_{(i, 1)}^{x} & K_{(i, 1)}^{y} & K_{(i, 1)}^{z}
\end{array}\right], \\
& \mathbf{K}_{B . C}^{l_{i}}=\operatorname{diag}\left[\begin{array}{llllll}
k_{(i, 2)}^{x} & k_{(i, 2)}^{y} & k_{(i, 2)}^{z} & K_{(i, 2)}^{x} & K_{(i, 2)}^{y} & K_{(i, 2)}^{z}
\end{array}\right] . \\
& \mathbf{K}_{c}^{i j}=\operatorname{diag}\left[\begin{array}{llllll}
k_{i j}^{x} & k_{i j}^{y} & k_{i j}^{z} & K_{i j}^{x} & K_{i j}^{y} & K_{i j}^{z}
\end{array}\right], \overline{\mathbf{U}}_{i}=\mathbf{R}_{i} \mathbf{U}_{i}, \mathbf{R}_{i}
\end{aligned}
$$

is the transformation matrix to transform $\mathbf{U}_{i}$ to the global coordinate system, and its form is as follows:

$$
\mathbf{R}_{i}=\left[\begin{array}{cccccc}
\cos \alpha_{i} & \sin \alpha_{i} & 0 & 0 & 0 & 0 \\
-\sin \alpha_{i} & \cos \alpha_{i} & 0 & 0 & 0 & 0 \\
0 & 0 & 1 & 0 & 0 & 0 \\
0 & 0 & 0 & \cos \alpha_{i} & \sin \alpha_{i} & 0 \\
0 & 0 & 0 & -\sin \alpha_{i} & \cos \alpha_{i} & 0 \\
0 & 0 & 0 & 0 & 0 & 1
\end{array}\right] .
$$

2.3. Solution for the Coupled Beams Structure. The displacements of the beam are described by $U_{i}, W_{i, y}, W_{i, z}$, and $\Theta_{i}$ in the $x-, y$-, $z$-directions and rotation angle around 


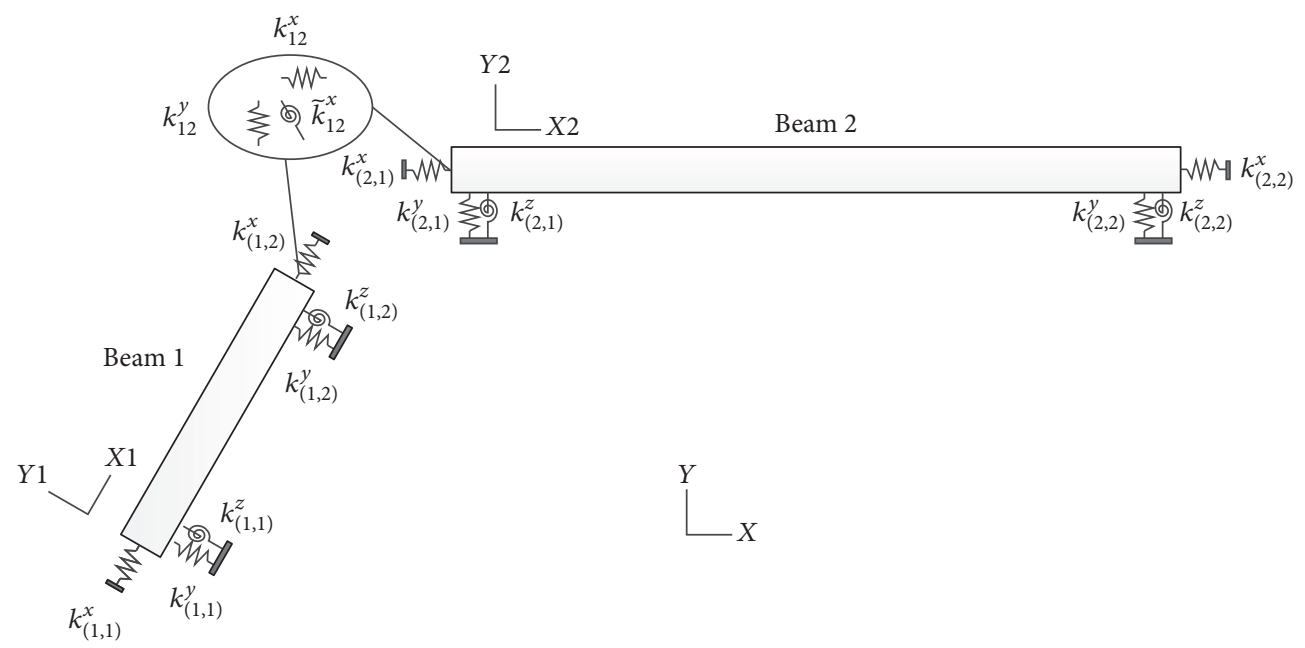

FIgURE 1: An illustration of a coupled beams system.

TABLE 1: The form of springs.

\begin{tabular}{|c|c|c|c|}
\hline & $\begin{array}{l}\text { The boundary springs } \\
\text { at the right ends of } \\
\text { beam } i\end{array}$ & $\begin{array}{l}\text { The coupling springs } \\
\text { at the junction of } \\
\text { beams } i \text { and } j\end{array}$ & $\begin{array}{c}\text { The boundary springs } \\
\text { at the left ends of } \\
\text { beam } j\end{array}$ \\
\hline$x$-direction spring & $k_{(i, 2)}^{x}$ & $k_{i j}^{x}$ & $k_{(j, 1)}^{x}$ \\
\hline$y$-direction spring & $k_{(i, 2)}^{y}$ & $k_{i j}^{y}$ & $k_{(j, 1)}^{y}$ \\
\hline$z$-direction spring & $k_{(i, 2)}^{z}$ & $k_{i j}^{z}$ & $k_{(j, 1)}^{z}$ \\
\hline $\begin{array}{l}\text { Around } x \text {-axis } \\
\text { rotational spring }\end{array}$ & $K_{(i, 2)}^{x}$ & $K_{i j}^{x}$ & $K_{(j, 1)}^{x}$ \\
\hline $\begin{array}{l}\text { Around } y \text {-axis } \\
\text { rotational spring }\end{array}$ & $K_{(i, 2)}^{y}$ & $K_{i j}^{y}$ & $K_{(j, 1)}^{y}$ \\
\hline $\begin{array}{l}\text { Around } z \text {-axis } \\
\text { rotational spring }\end{array}$ & $K_{(i, 2)}^{z}$ & $K_{i j}^{z}$ & $K_{(j, 1)}^{z}$ \\
\hline
\end{tabular}

$x$-direction. And they can be written in the form of the improved Fourier series as follows:

$$
\begin{aligned}
& U_{i}(x, t)=\left(\sum_{m=0}^{M} A_{u_{i}}^{m} \cos \left(\lambda_{i m} x\right)+\boldsymbol{\alpha}_{u_{i}} \cdot \boldsymbol{\xi}_{u_{i}}^{T}(x)\right) e^{j \omega t}, \\
& W_{i, y}(x, t) \\
& \quad=\left(\sum_{m=0}^{M} A_{w_{i, y}}^{m} \cos \left(\lambda_{i m} x\right)+\boldsymbol{\alpha}_{w_{i, y}} \cdot \boldsymbol{\xi}_{w_{i, y}}^{T}(x)\right) e^{j \omega t}, \\
& W_{i, z}(x, t) \\
& \quad=\left(\sum_{m=0}^{M} A_{w_{i, z}}^{m} \cos \left(\lambda_{i m} x\right)+\boldsymbol{\alpha}_{w_{i, z}} \cdot \boldsymbol{\xi}_{w_{i, z}}^{T}(x)\right) e^{j \omega t}, \\
& \Theta_{i}(x, t)=\left(\sum_{m=0}^{M} A_{\theta_{i}}^{m} \cos \left(\lambda_{i m} x\right)+\boldsymbol{\alpha}_{\theta_{i}} \cdot \boldsymbol{\xi}_{\theta_{i}}^{T}(x)\right) e^{j \omega t,}
\end{aligned}
$$

where $\omega$ is the angular frequency, $t$ represents time, $\lambda_{i m}=$ $m \pi / L, A_{u_{i}}^{m}, A_{w_{i, y}}^{m}, A_{w_{i, z}}^{m}$, and $A_{\theta_{i}}^{m}$ are the Fourier expanded coefficient, and $\boldsymbol{\alpha}_{u_{i}}, \boldsymbol{\alpha}_{w_{i, y}}, \boldsymbol{\alpha}_{w_{i, z}}$, and $\boldsymbol{\alpha}_{\theta_{i}}$ are the expanded coefficients of the auxiliary functions. They can be solved by the Rayleigh-Ritz procedure. $\xi(x)$ are the auxiliary functions which can remove any potential discontinuities of the original displacements and effectively enhance the convergence of the result. In this paper, these auxiliary functions are specially selected as

$$
\begin{aligned}
\xi_{u_{i}}(x) & =\xi_{\theta_{i}}(x)=\left\{\xi_{1}(x), \xi_{2}(x)\right\}, \\
\xi_{w_{i, y}}(x) & =\xi_{w_{i, z}}(x)=\left\{\xi_{1}(x), \xi_{2}(x), \xi_{3}(x), \xi_{4}(x)\right\}, \\
\xi & =\left[\begin{array}{l}
\xi_{1}(x) \\
\xi_{2}(x) \\
\xi_{3}(x) \\
\xi_{4}(x)
\end{array}\right] \\
& =\left[\begin{array}{c}
\frac{6 L x-2 L^{2}-3 x^{2}}{6 L} \\
\frac{3 x^{2}-L^{2}}{6 L} \\
\frac{-15 x^{4}+60 L x^{3}-60 L^{2} x^{2}+8 L^{4}}{360 L} \\
\frac{15 x^{4}-30 L^{2} x^{2}+7 L^{4}}{360 L}
\end{array}\right] .
\end{aligned}
$$


Substituting (2)-(3) and (6) together with the admissible functions into (1) and then performing the Rayleigh-Ritz procedure, the governing eigenvalue equation can be obtained and given as

$$
\left(\mathbf{K}-\omega^{2} \mathbf{M}\right) \mathbf{C}=0
$$

where the matrix $\mathbf{K}$ is the stiffness matrix of the system and its form is as follows:

$$
\mathbf{K}=\left[\begin{array}{cccccc}
\mathbf{K}_{11} & \cdots & \mathbf{K}_{1 i} & \cdots & \mathbf{K}_{1 j} & \cdots \\
& \ddots & \vdots & \vdots & \vdots & \cdots \\
& & \mathbf{K}_{i i} & \vdots & \mathbf{K}_{i j} & \cdots \\
& & & \ddots & \vdots & \cdots \\
& & & & \mathbf{K}_{j j} & \cdots \\
& & & & & \ddots
\end{array}\right]
$$

in which $\mathbf{K}_{i i}$ represents the total stiffness matrix of the $i$ th beam. The form is as follows:

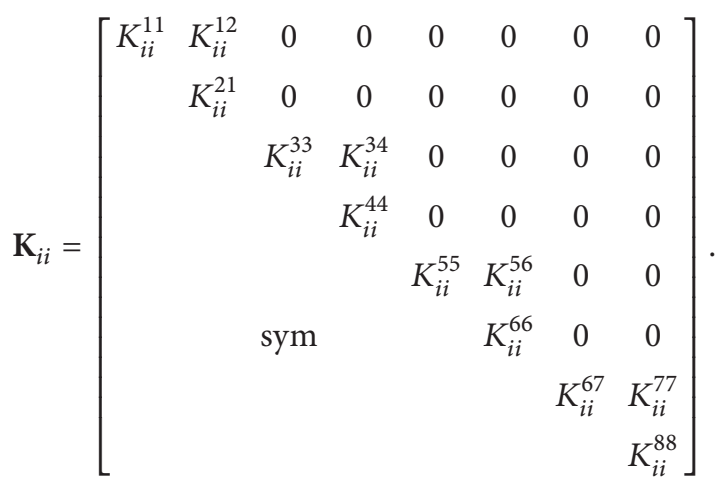

The matrix $\mathbf{K}_{i j}$ is the coupling stiffness matrix caused by the coupling spring between the $i$ th and $j$ th beams, and its form is as follows:

$$
\mathbf{K}_{i j}=\left[\begin{array}{cccccccc}
K_{i j}^{11} & K_{i j}^{12} & K_{i j}^{13} & K_{i j}^{14} & 0 & 0 & 0 & 0 \\
K_{i j}^{21} & K_{i j}^{22} & K_{i j}^{23} & K_{i j}^{24} & 0 & 0 & 0 & 0 \\
K_{i j}^{31} & K_{i j}^{32} & K_{i j}^{33} & K_{i j}^{34} & 0 & 0 & 0 & 0 \\
K_{i j}^{41} & K_{i j}^{42} & K_{i j}^{43} & K_{i j}^{44} & 0 & 0 & 0 & 0 \\
0 & 0 & 0 & 0 & K_{i j}^{55} & K_{i j}^{56} & K_{i j}^{57} & K_{i j}^{58} \\
0 & 0 & 0 & 0 & K_{i j}^{65} & K_{i j}^{66} & K_{i j}^{67} & K_{i j}^{68} \\
0 & 0 & 0 & 0 & K_{i j}^{75} & K_{i j}^{76} & K_{i j}^{77} & K_{i j}^{78} \\
0 & 0 & 0 & 0 & K_{i j}^{85} & K_{i j}^{86} & K_{i j}^{87} & K_{i j}^{88}
\end{array}\right] .
$$

The detail form of the above equation can be found in Appendix A.

The system mass matrix $\mathbf{M}$ can be written as

$$
\mathbf{M}=\operatorname{diag}\left[\begin{array}{llll}
\mathbf{M}_{1} & \cdots & \mathbf{M}_{i} & \cdots
\end{array}\right]
$$

where $\mathbf{M}_{i}$ is the mass matrix of the beam $i$ and can be expressed as

$\mathbf{M}_{i}$

$$
=\left[\begin{array}{cccccccc}
M_{i}^{11} & M_{i}^{12} & 0 & 0 & 0 & 0 & 0 & 0 \\
& M_{i}^{22} & 0 & 0 & 0 & 0 & 0 & 0 \\
& & M_{i}^{33} & M_{i}^{34} & 0 & 0 & 0 & 0 \\
& & & M_{i}^{44} & 0 & 0 & 0 & 0 \\
& & & & M_{i}^{55} & M_{i}^{56} & 0 & 0 \\
& & & & & M_{i}^{66} & 0 & 0 \\
& & & & & & M_{i}^{77} & M_{i}^{78} \\
& & & & & & & M_{i}^{88}
\end{array}\right] .
$$

The detail form of the above equation can be found in Appendix B.

The definition of the coefficient vector $\mathbf{C}$ in (8) is

$$
\mathbf{C}=\left[\begin{array}{llll}
\mathbf{C}_{1} & \cdots & \mathbf{C}_{i} & \cdots
\end{array}\right]^{T},
$$

where

$$
\begin{aligned}
& \mathbf{C}_{i}=\left[\begin{array}{llllllll}
\mathbf{A}_{u_{i}} & \boldsymbol{\alpha}_{u_{i}} & \mathbf{A}_{w_{i, y}} & \boldsymbol{\alpha}_{w_{i, y}} & \mathbf{A}_{w_{i, z}} & \boldsymbol{\alpha}_{w_{i, z}} & \mathbf{A}_{\theta_{i}} & \boldsymbol{\alpha}_{\theta_{i}}
\end{array}\right], \\
& \mathbf{A}_{u_{i}}=\left[A_{u_{i}}^{0}, A_{u_{i}}^{1}, \ldots, A_{u_{i}}^{M}\right] \text {, } \\
& \boldsymbol{\alpha}_{u_{i}}=\left[\alpha_{u_{i}}^{1}, \alpha_{u_{i}}^{2}\right] \text {, } \\
& \mathbf{A}_{w_{i, y}}=\left[A_{w_{i, y}}^{0}, A_{w_{i, y}}^{1}, \ldots, A_{w_{i, y}}^{M}\right] \text {, } \\
& \boldsymbol{\alpha}_{w_{i, y}}=\left[\alpha_{w_{i, y}}^{1}, \alpha_{w_{i, y}}^{2}, \alpha_{w_{i, y}}^{3}, \alpha_{w_{i, y}}^{4}\right] \text {, } \\
& \mathbf{A}_{w_{i, z}}=\left[A_{w_{i, z}}^{0}, A_{w_{i, z}}^{1}, \ldots, A_{w_{i, z}}^{M}\right] \text {, } \\
& \boldsymbol{\alpha}_{w_{i, z}}=\left[\alpha_{w_{i, z}}^{1}, \alpha_{w_{i, z}}^{2}, \alpha_{w_{i, z}}^{3}, \alpha_{w_{i, z}}^{4}\right] \text {, } \\
& \mathbf{A}_{\theta_{i}}=\left[A_{\theta_{i}}^{0}, A_{\theta_{i}}^{1}, \ldots, A_{\theta_{i}}^{M}\right] \text {, } \\
& \boldsymbol{\alpha}_{\theta_{i}}=\left[\alpha_{\theta_{i}}^{1}, \alpha_{\theta_{i}}^{2}\right] \text {. }
\end{aligned}
$$

All the natural frequencies and mode shapes of the coupled beams can be obtained by solving (8), which is a standard characteristic equation.

\section{Numerical Example and Discussions}

In this section, several examples are presented to verify the accuracy and reliability of the present method. Firstly, the convergence of the present solution is checked and excellent accuracy is validated through comparison of the results obtained from the FEM. Then coupled beams with arbitrary coupling angle are studied. Influence of coupling springs is discussed as well. The properties for these coupled beams structures are summarized in Table 2. 
TABLE 2: Parameters of each beam.

\begin{tabular}{lccc}
\hline Parameter & Unit & Beam 1 & Beam 2 \\
\hline$L$ & $\mathrm{~m}$ & 0.24 & 0.8 \\
$S$ & $\mathrm{~m}^{2}$ & 0.0009 & 0.0009 \\
$I$ & $\mathrm{~m}^{4}$ & $6.75 e-8$ & $6.75 e-8$ \\
$E$ & $\mathrm{Nm}^{-2}$ & $2.1 e 11$ & $2.1 e 11$ \\
$\rho$ & $\mathrm{Kgm}^{-3}$ & 7800 & 7800 \\
\hline
\end{tabular}
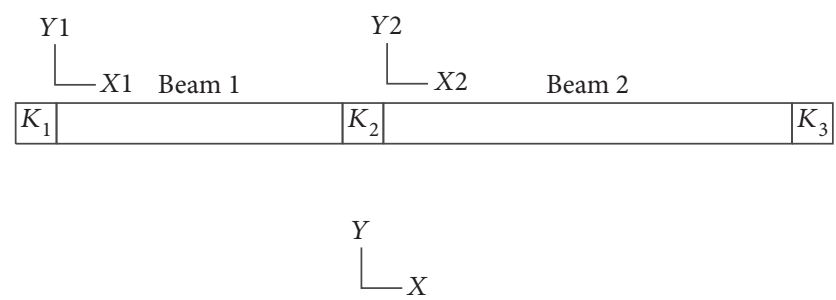

FIgURE 2: Coupling beam structure with $0^{\circ}$ angle.

3.1. Convergence and Validation Study. Theoretically, there are infinite terms in the improved Fourier series solution. However, the series is numerically truncated and only finite terms are counted in actual calculations. The convergence of the present method will be checked. As an example, consider two beams connected together at $0^{\circ}$ angle, as shown in Figure 2. Table 3 shows the first eight frequencies of the coupled beams with some classical boundary conditions, including CC, F-F, and S-S, are derived by different truncation number $M$. It is obvious that the natural frequencies converge quickly with the increasing truncated number. It can be also found that the results obtained by present method converge well at $M=12$. Therefore, the truncated number will be uniformly selected as $M=12$. And also, an excellent agreement of comparisons between the results and those from FEM shows the accuracy of present method. Some selected mode shapes for the $\mathrm{C}-\mathrm{C}$ supported structure are given in Figure 3 . It is obvious that the two sets of modes are essentially identical and the coupled beams are commonly coupled.

3.2. Two Coupled Beams with Arbitrary Angle. In order to illustrate the application of the current method, the studies on free vibration of the coupled beams with a $45^{\circ}$ and $90^{\circ}$ coupling angle are carried out, as shown in Figure 4 . The left end of beam 1 and the right end of beam 2 are clamped. Table 4 shows the comparison of nature frequencies obtained by present method and FEM. Some selected mode shapes are shown in Figures 5 and 6 . It is seen that very good agreement of the result is obtained. The comparisons in Table 4 and Figures 5 and 6 indicated that the current analysis for coupled beams with various coupling angles is accurate and reliable.

3.3. Two Coupled Beams with Elastically Coupling Condition. In this section, the effects of the coupling spring on the mode shape of the coupled beams are investigated. Four types of coupling conditions as shown in Table 5 are considered in this part. The fourth mode shape of the coupled beams with various coupling conditions is present in Figure 7. Figure 7(a) shows that the mode shape is uncoupling and independent from each other when the coupling spring stiffness is $K=$ 0 . When the coupling spring stiffness changes from $1 e 6$ to $1 e 8$, because of the elastic coupling, the displacement on the beams is no longer continuous across the junction. And there is a trend for the coupled beams from weak-coupling to strong-coupling. When the coupling spring stiffness is $K=$ $1 E 10$, the coupled beams realized the rigidity connection.

\section{Application of Present Method to the Propulsion Shafting System}

In this section, the propulsion shafting system will be taken as an example to illustrate the application of present method in practice. The shafting is assumed to be the beam structure with arbitrary boundary conditions. Thrust bearing is simulated as a beam which can be both transmit force and bending moment. The propeller is considered to be the lumped mass and the middle bearing and stern bearing are considered to be the linear springs. The propulsion shafting is simplified in Figure 8 and the properties for shafting are summarized in Table 6.

4.1. Vibration Characteristic of the Propeller Shafting System. For propulsion shafting with a propeller, a lumped mass is adopted, it needs to consider the influence of the lumped mass to the mass matrix of coupling system, and the energy of lumped mass is as follows:

$$
\begin{aligned}
T_{M_{4}} & =\left(\frac{1}{2} m_{4}\left(\frac{\partial U_{4}}{\partial t}\right)^{2}+\frac{1}{2} m_{4}\left(\frac{\partial W_{4, y}}{\partial t}\right)^{2}\right. \\
+ & \left.\frac{1}{2} m_{4}\left(\frac{\partial W_{4, z}}{\partial t}\right)^{2}+\frac{1}{2} m_{4} r^{2}\left(\frac{\partial \theta_{4}}{\partial t}\right)^{2}\right)_{x=l_{4}} .
\end{aligned}
$$

Through (1) to (8), we can get the vibration characteristics of propulsion shafting under multisupport bearings with propeller.

In Table 7 , the nature frequencies of the propulsion shafting are compared to those obtained by FEM. From Table 7, we can see that the present results agree well with the referential data. The deviation is small and does not exceed $2.5 \%$ for the worst case, which validates the accuracy and feasibility of present method for propulsion shafting system. Some selected mode shapes are shown in Figure 9.

4.2. Vibration Isolator. Longitudinal vibration isolator can be achieved by assigning the $x$-direction springs between shafting and thrust bearing at proper stiffness value. In this section, the damping effect of the isolator with different stiffness valve is studied. The stiffness values were separately taken as $1 E 9 \mathrm{~N} / \mathrm{m}, 5 E 8 \mathrm{~N} / \mathrm{m}, 1 E 8 \mathrm{~N} / \mathrm{m}$, and $5 E 7 \mathrm{~N} / \mathrm{m}$. From Table 8 , we can see that, with the decreasing of stiffness valve, the two natural frequencies of longitudinal vibration are gradually reduced. The simulation of the isolator can be achieved. 


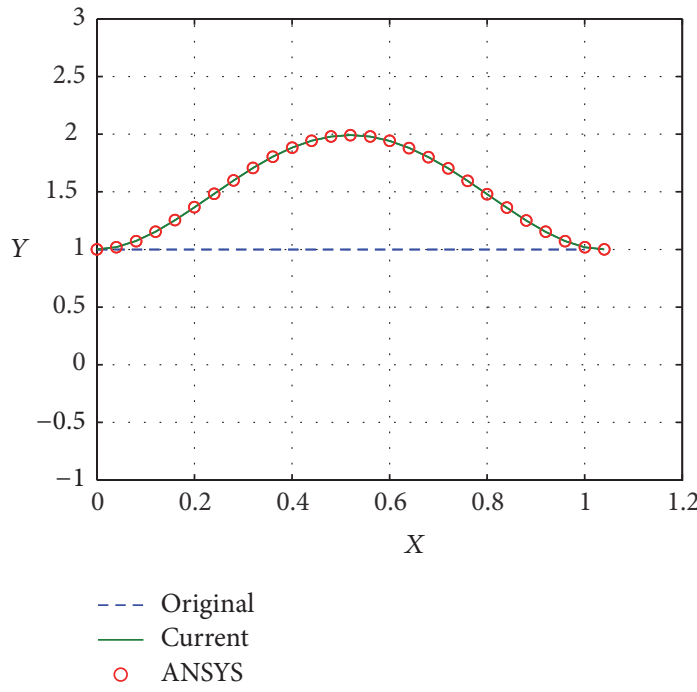

(a)

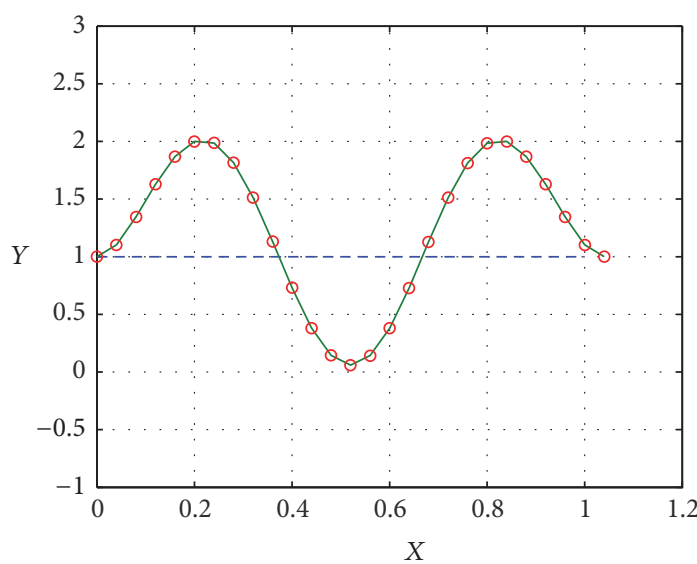

$$
\begin{array}{cl}
--- & \text { Original } \\
- & \text { Current } \\
\circ & \text { ANSYS }
\end{array}
$$

(c)

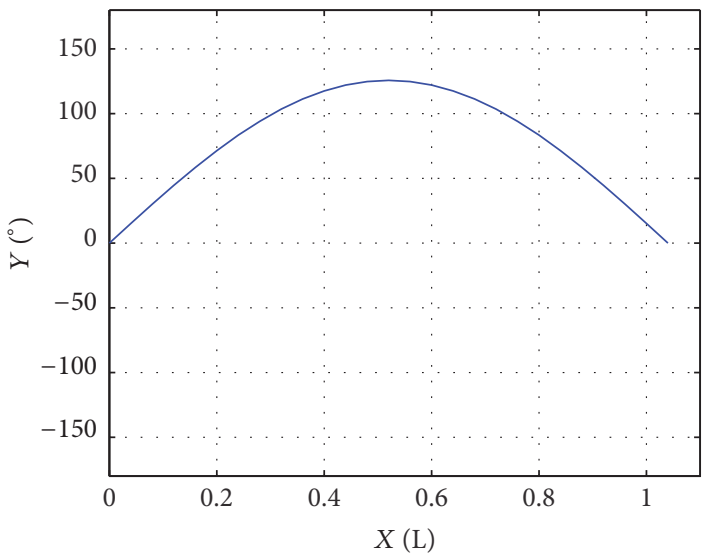

(e)

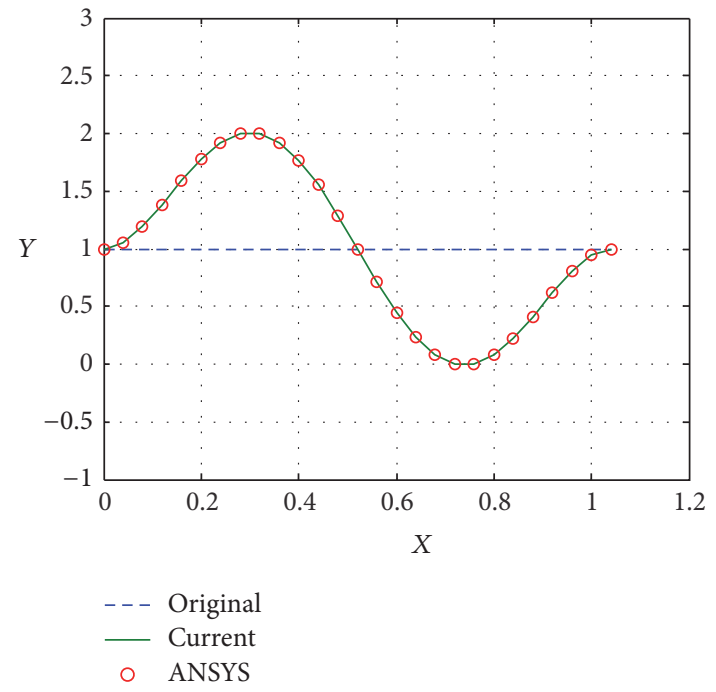

(b)

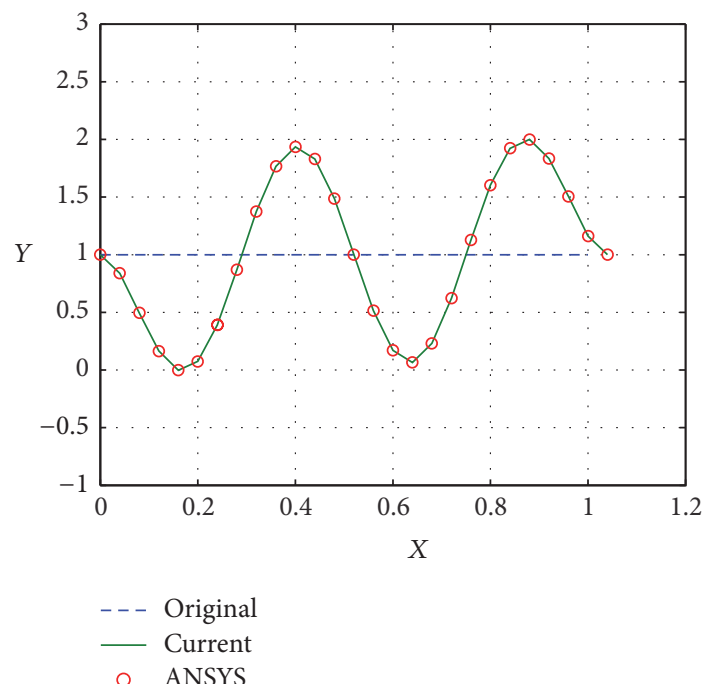

(d)

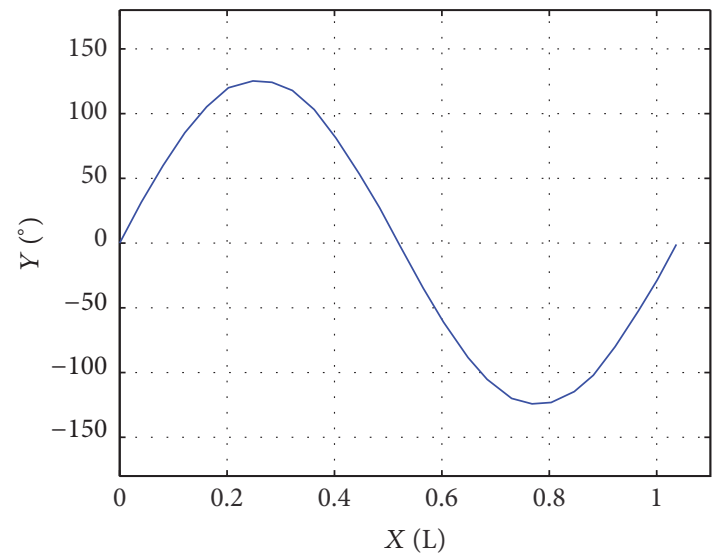

(f)

Figure 3: The modes of coupled beams with C-C: (a) the first mode, (b) the second mode, (c) the third mode, (d) the fourth mode, (e) first rotational vibration, (f) second rotational vibration. 
TABLE 3: The natural frequency for coupled beams with various boundary condition $\mathrm{f} / \mathrm{Hz}$.

\begin{tabular}{|c|c|c|c|c|c|c|c|}
\hline Boundary conditions & Mode & $M=6$ & $M=8$ & $M=10$ & $M=12$ & ANSYS & Errors/\% \\
\hline \multirow{8}{*}{$\mathrm{C}-\mathrm{C}$} & 1 & 84.51 & 85.15 & 85.48 & 85.50 & 85.646 & 0.17 \\
\hline & 2 & 235.15 & 235.26 & 235.61 & 236.10 & 237.19 & 0.46 \\
\hline & 3 & 459.58 & 461.71 & 461.97 & 462.17 & 468.27 & 1.32 \\
\hline & 4 & 773.66 & 773.72 & 773.98 & 774.11 & 781.46 & 0.95 \\
\hline & 5 & 1159.23 & 1160.05 & 1160.86 & 1160.88 & 1181.4 & 1.77 \\
\hline & 6 & 1641.33 & 1642.94 & 1643.21 & 1643.32 & 1674.1 & 1.87 \\
\hline & 7 & 2220.49 & 2221.01 & 2225.91 & 2226.40 & 2266.7 & 1.81 \\
\hline & 8 & 2917.79 & 2918.03 & 2923.76 & 2923.94 & 2967.7 & 1.50 \\
\hline \multirow{8}{*}{ S-S } & 1 & 37.40 & 37.57 & 37.70 & 37.73 & 37.75 & 0.06 \\
\hline & 2 & 150.26 & 150.31 & 150.58 & 150.82 & 151.56 & 0.49 \\
\hline & 3 & 339.04 & 339.12 & 339.40 & 339.53 & 343.15 & 1.07 \\
\hline & 4 & 603.43 & 603.48 & 603.54 & 604.15 & 615.40 & 1.86 \\
\hline & 5 & 962.25 & 962.49 & 962.78 & 962.88 & 972.43 & 0.99 \\
\hline & 6 & 1384.01 & 1387.52 & 1387.63 & 1390.25 & 1419.70 & 2.12 \\
\hline & 7 & 1937.93 & 1938.41 & 1944.44 & 1945.21 & 1963.90 & 0.96 \\
\hline & 8 & 2569.58 & 2570.04 & 2583.40 & 2586.49 & 2613.10 & 1.03 \\
\hline \multirow{8}{*}{ F-F } & 1 & 84.54 & 85.32 & 85.46 & 85.49 & 85.56 & 0.09 \\
\hline & 2 & 234.93 & 235.29 & 235.64 & 235.69 & 236.79 & 0.47 \\
\hline & 3 & 462.03 & 462.03 & 462.30 & 462.36 & 467.15 & 1.04 \\
\hline & 4 & 763.66 & 763.86 & 764.72 & 765.61 & 779.02 & 1.75 \\
\hline & 5 & 1150.81 & 1151.17 & 1151.88 & 1152.57 & 1176.80 & 2.10 \\
\hline & 6 & 1633.81 & 1633.82 & 1634.62 & 1634.73 & 1666.10 & 1.92 \\
\hline & 7 & 2221.59 & 2221.78 & 2222.19 & 2222.43 & 2253.90 & 1.42 \\
\hline & 8 & 2924.93 & 2925.99 & 2926.58 & 2926.61 & 2948.10 & 0.73 \\
\hline
\end{tabular}

TABLE 4: The natural frequencies for the coupled beams with $90^{\circ}$ and $45^{\circ}$ coupling angle (f/Hz).

\begin{tabular}{|c|c|c|c|c|c|c|}
\hline Angle & Model & 1 & 2 & 3 & 4 & 5 \\
\hline \multirow{7}{*}{$\Theta=90^{\circ}$} & Current & 91.35 & 129.47 & 192.02 & 361.90 & 396.75 \\
\hline & ANSYS & 91.94 & 129.91 & 193.24 & 365.96 & 400.69 \\
\hline & Error\% & 0.64 & 0.34 & 0.64 & 1.12 & 0.99 \\
\hline & Model & 6 & 7 & 8 & 9 & 10 \\
\hline & Current & 712.21 & 738.02 & 1136.14 & 1161.20 & 1312.90 \\
\hline & ANSYS & 727.85 & 754.31 & 1158.00 & 1183.50 & 1343.50 \\
\hline & Error\% & 2.20 & 2.21 & 1.92 & 1.92 & 2.33 \\
\hline \multirow{7}{*}{$\Theta=45^{\circ}$} & Current & 86.63 & 128.99 & 219.10 & 362.03 & 430.76 \\
\hline & ANSYS & 86.15 & 128.54 & 217.32 & 358.03 & 425.28 \\
\hline & Error\% & 0.56 & 0.35 & 0.82 & 1.12 & 1.29 \\
\hline & Model & 6 & 7 & 8 & 9 & 10 \\
\hline & Current & 718.88 & 762.77 & 1106.60 & 1177.80 & 1191.00 \\
\hline & ANSYS & 703.84 & 755.18 & 1096.20 & 1154.53 & 1170.87 \\
\hline & Error\% & 2.14 & 1.00 & 0.95 & 2.02 & 1.72 \\
\hline
\end{tabular}

4.3. Dynamic Vibration Absorber. Dynamic vibration absorbers are commonly designed and tuned to suppress vibrations of one vibration mode of a vibrating structure. As shown in Figure 10, the spring-mass systems which are attached to propulsion shafting are simulated as the dynamic vibration absorbers.
The mass is $M_{a}$ and the stiffness coefficient of the spring between the mass and the beam is $K_{a}$ :

$$
\begin{aligned}
M_{a} & =0.05 m_{s}, \\
K & =\left(2 \pi f_{a}\right)^{2} M_{a},
\end{aligned}
$$




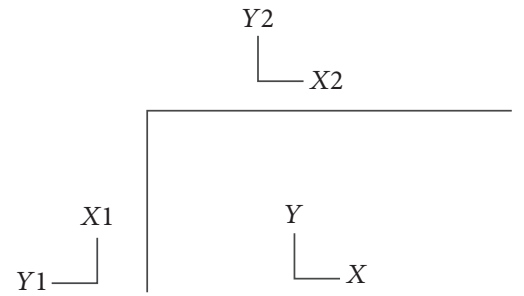

Coupling angle: $90^{\circ}$

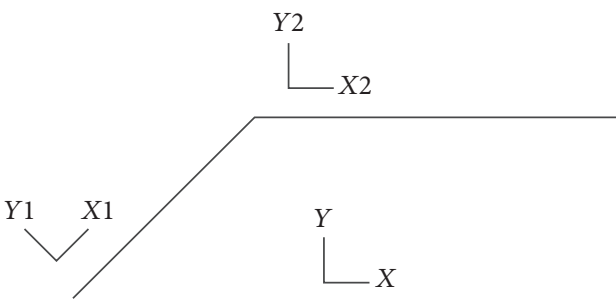

Coupling angle: $45^{\circ}$

Figure 4: The coupled beams with $90^{\circ}$ and $45^{\circ}$ coupling angle.

TABLE 5: Four cases of coupling condition for coupled beams.

\begin{tabular}{|c|c|c|c|c|c|c|}
\hline Four cases & $\begin{array}{c}x \text {-direction } \\
\text { spring }\end{array}$ & $\begin{array}{l}y \text {-direction } \\
\text { spring }\end{array}$ & $\begin{array}{l}z \text {-direction } \\
\text { spring }\end{array}$ & $\begin{array}{c}\text { Around } \\
x \text {-axis } \\
\text { rotational } \\
\text { spring }\end{array}$ & $\begin{array}{l}\text { Around } \\
y \text {-axis } \\
\text { rotational } \\
\text { spring }\end{array}$ & $\begin{array}{l}\text { Around } \\
z \text {-axis } \\
\text { rotational } \\
\text { spring }\end{array}$ \\
\hline Case 1 & 0 & 0 & 0 & 0 & 0 & 0 \\
\hline Case 2 & $1 e 6$ & $1 e 6$ & $1 e 6$ & $1 e 6$ & $1 e 6$ & $1 e 6$ \\
\hline Case 3 & $1 e 8$ & $1 e 8$ & $1 e 8$ & $1 e 8$ & $1 e 8$ & $1 e 8$ \\
\hline Case 4 & $1 e 10$ & $1 e 10$ & $1 e 10$ & $1 e 10$ & $1 e 10$ & $1 e 10$ \\
\hline
\end{tabular}

TABLE 6: Parameters of propulsion shafting.

\begin{tabular}{lccc}
\hline Parameter & Unit & Beam 1 & Beam 2 \\
\hline$L$ & $\mathrm{~m}$ & 0.4 & 2.68 \\
$S$ & $\mathrm{~m}^{2}$ & $3.14 e-4$ & $3.14 e-4$ \\
$I$ & $\mathrm{~m}^{4}$ & $7.85 e-009$ & $7.85 e-009$ \\
$E$ & $\mathrm{~N} / \mathrm{m}^{2}$ & $2.1 e 11$ & $2.1 e 11$ \\
$\rho$ & $\mathrm{kg} / \mathrm{m}^{3}$ & 7800 & 7800 \\
\hline
\end{tabular}

where $m_{s}$ is the mass of the shafting and $f_{a}$ is the frequency of the vibration mode which is suppressed.

The displacement of the mass has a form of

$$
\mathbf{X}=X e^{j \omega t} .
$$

Accordingly, the kinetic energy and the potential energy stored in the spring-mass system can be described as

$$
\begin{aligned}
V_{a} & =\frac{1}{2} k_{a}\left(W_{2, y}(a)-X\right)^{2}, \\
T_{a} & =\frac{1}{2} m_{a} \dot{X}^{2} .
\end{aligned}
$$

Substituting (18)-(20) into the Lagrangian energy function, we can get the vibration characteristics of propulsion shafting with dynamic vibration absorbers.

In Table 9, we can see that there are two natural frequencies on both sides of the absorbency frequency after the dynamic vibration absorber is attached, and the other natural frequencies remain unchanged. Therefore, the frequency characteristic of the dynamic vibration absorbers is met. Accordingly the spring-mass system can achieve the simulation of the vibration absorber.

\section{Conclusions}

An improved Fourier series method has been developed for the free vibration analysis of three-dimensional coupled beams with arbitrary coupling angle. The displacement and rotation of the structure are expressed as the Fourier cosine series and closed-form auxiliary functions. On the basis of energy functional of the structure elements, the solutions are obtained using Rayleigh-Ritz procedure. By using the present method, the three-dimensional coupled beams with arbitrary coupling angle and boundary conditions can be solved in a unified form. The accuracy and convergence of the present method are demonstrated by the FEM results. Based on this, the methodology is expressed to be applicable to vibration analysis for the propulsion shafting system and proved accurate for the FEM result as reference and obtained an efficient solution for the vibration suppression devices.

\section{Appendix}

\section{A. Stiffness Matrices}

Various stiffness matrices are represented as

$$
\begin{aligned}
& K_{i i}^{11}=\int_{0}^{l_{i}} E_{i} S_{i} \varphi_{u_{i}}^{T T}(x) \varphi_{u_{i}}^{\prime}(x) d x+k_{(i, 1)}^{x} \varphi_{u_{i}}^{T}(0) \varphi_{u_{i}}^{\prime}(0) \\
& +k_{(i, 2)}^{x} \varphi_{u_{i}}^{T}\left(l_{i}\right) \varphi_{u_{i}}^{\prime}\left(l_{i}\right)+\sum_{j=1}^{n}\left(1-\delta_{i j}\right) \\
& \cdot\left(k_{12}^{x} \cos ^{2} \alpha_{i}+k_{12}^{y} \sin ^{2} \alpha_{i}\right)\left[\varphi_{u_{i}}^{T}\left(x_{0}\right) \varphi_{u_{i}}^{\prime}\left(x_{0}\right)\right], \\
& K_{i i}^{12}=\int_{0}^{l_{i}} E_{i} S_{i} \varphi_{u_{i}}^{T T}(x) \xi_{u_{i}}^{\prime}(x) d x+k_{(i, 1)}^{x} \varphi_{u_{i}}^{T}(0) \xi_{u_{i}}^{\prime}(0)
\end{aligned}
$$



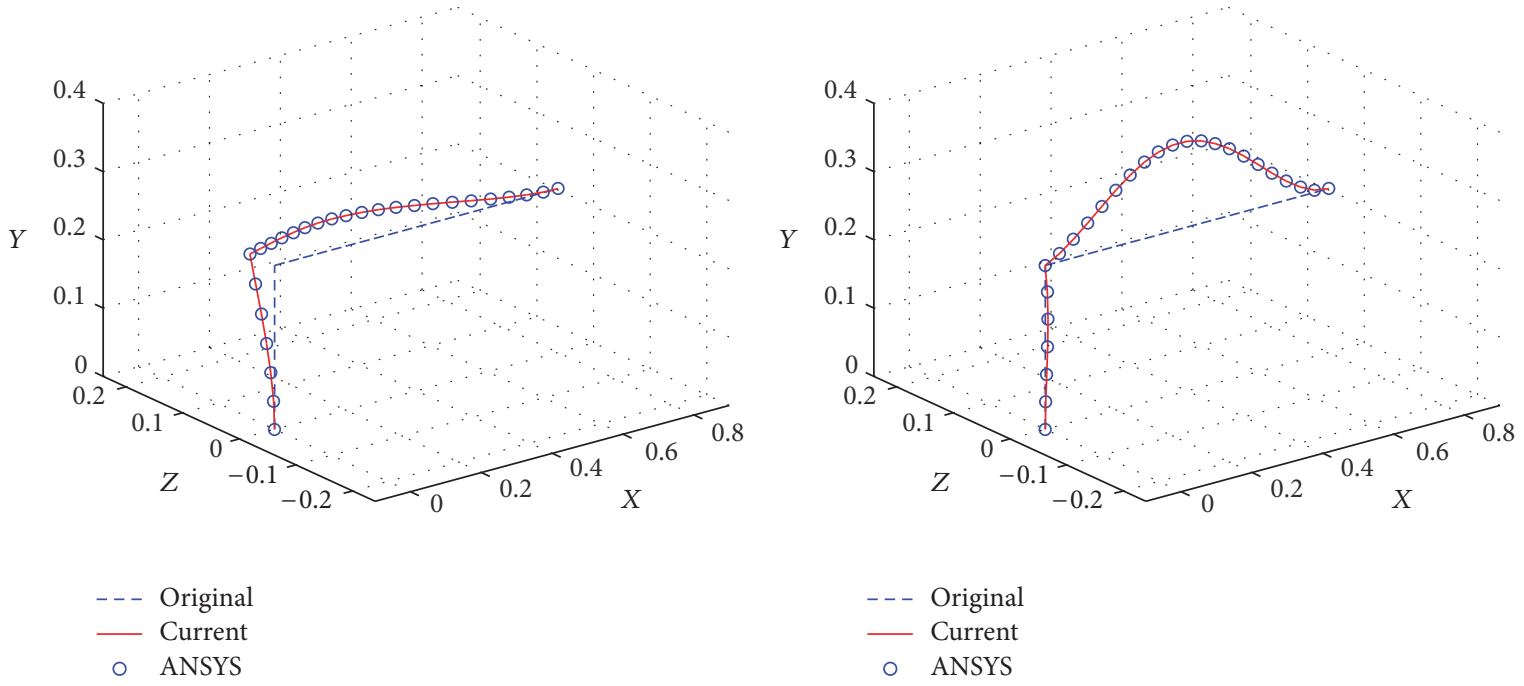

(a)

(b)
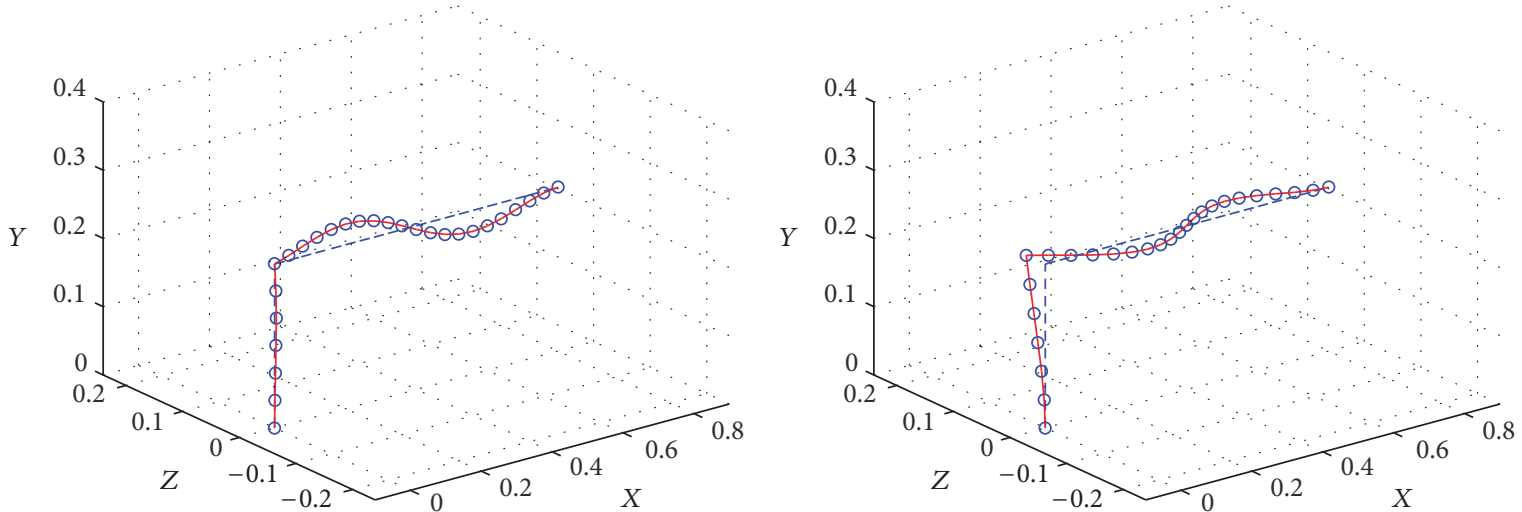

$\begin{array}{cc}--- & \text { Original } \\ - & \text { Current } \\ \circ & \text { ANSYS }\end{array}$

- - Original

- Current

- ANSYS

(c)

(d)
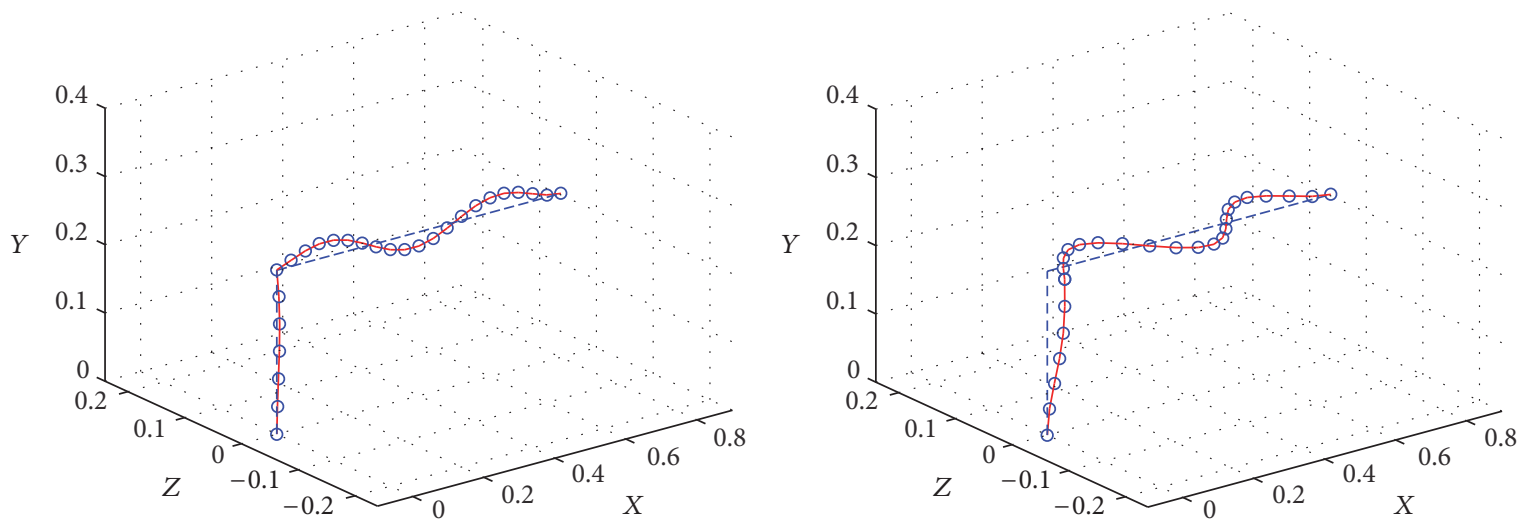

-- - Original
- Current
- ANSYS

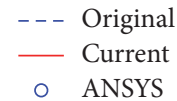

(e)

FIGURE 5: Continued. 


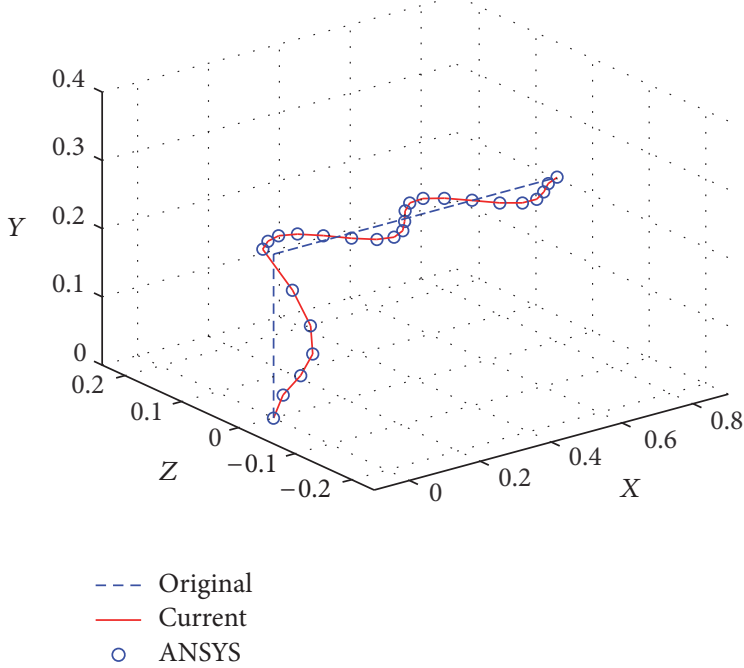

(g)

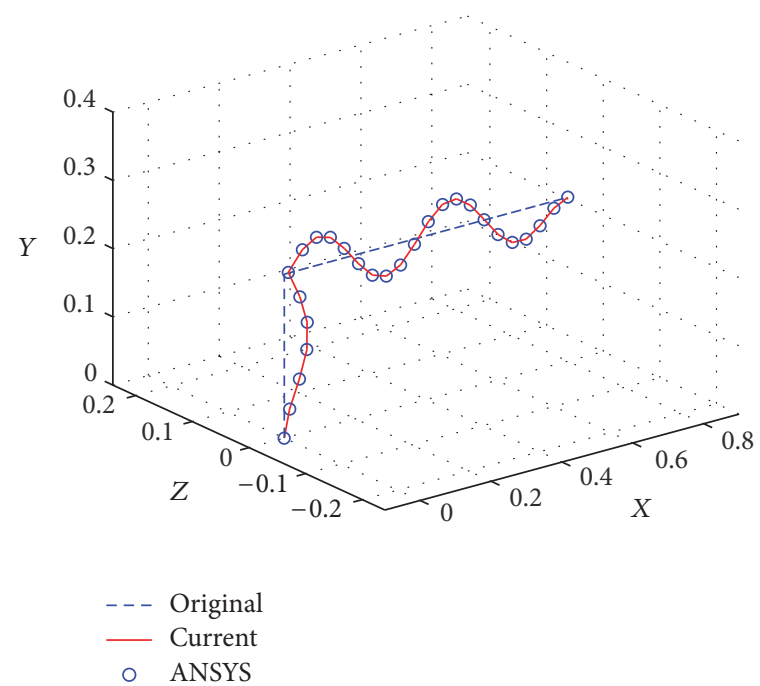

(h)

Figure 5: The first eight modes of coupled beams with $90^{\circ}$ coupling angle: (a) the first mode, (b) the second mode, (c) the third mode, (d) the fourth mode, (e) the fifth mode, (f) the sixth mode, (g) the seventh mode, and (h) the eighth mode.

TABLE 7: The first ten natural frequencies of propulsion shafting $\mathrm{f} / \mathrm{Hz}$.

\begin{tabular}{lccccc}
\hline Model & 1 & 2 & 3 & 4 & 5 \\
\hline Current & 26.42 & 27.93 & 55 & 79.02 & 78.66 \\
ANSYS & 26.53 & 27.86 & 54.74 & 0.45 & 81.87 \\
Error\% & 0.42 & 0.26 & 0.47 & 9 & 0.65 \\
\hline Model & 6 & 7 & 8 & 175.84 & 10 \\
\hline Current & 134.89 & 146.75 & 174.02 & 179.71 & 271.76 \\
ANSYS & 133.4 & 145.8 & 1.03 & 1.14 & 266.28 \\
Error\% & 1.11 & 0.64 & & 2.02 \\
\hline
\end{tabular}

TABLE 8: The effect of the stiffness value of the isolator.

\begin{tabular}{lcccc}
\hline $\begin{array}{l}\text { Longitudinal } \\
\text { vibration frequency }\end{array}$ & $1 E 9$ & $5 E 8$ & $1 E 8$ & $5 E 7$ \\
\hline 1 & 1376.92 & 1374.99 & 1361.18 & 1336.97 \\
2 & 2381.14 & 2380.01 & 2368.70 & 2346.83 \\
\hline
\end{tabular}

$$
\begin{aligned}
& +k_{(i, 2)}^{x} \varphi_{u_{i}}^{T}\left(l_{i}\right) \xi_{u_{i}}^{\prime}\left(l_{i}\right)+\sum_{j=1}^{n}\left(1-\delta_{i j}\right) \\
& \cdot\left(k_{12}^{x} \cos ^{2} \alpha_{i}+k_{12}^{y} \sin ^{2} \alpha_{i}\right)\left[\varphi_{u_{i}}^{T}\left(x_{0}\right) \xi_{u_{i}}^{\prime}\left(x_{0}\right)\right] \\
& K_{i i}^{13}=\sum_{j=1}^{n}\left(1-\delta_{i j}\right)\left(-k_{12}^{x}+k_{12}^{y}\right) \sin \alpha_{i} \cos \alpha_{i} \\
& \cdot\left[\varphi_{u_{i}}^{T}\left(x_{0}\right) \varphi_{w_{i, y}}^{\prime}\left(x_{0}\right)\right] \\
& K_{i i}^{14}=\sum_{j=1}^{n}\left(1-\delta_{i j}\right)\left(-k_{12}^{x}+k_{12}^{y}\right) \sin \alpha_{i} \cos \alpha_{i}\left[\varphi_{u_{i}}^{T}\left(x_{0}\right)\right. \\
& \left.\cdot \xi_{w_{i, y}}^{\prime}\left(x_{0}\right)\right]
\end{aligned}
$$

TABLE 9: The frequency of the shafting with absorber f/Hz.

\begin{tabular}{lcc}
\hline Model & Origin model & Absorber model \\
\hline 1 & 26.42 & 26.53 \\
2 & 27.93 & 27.81 \\
& & 30.44 \\
3 & 55 & 55.16 \\
4 & 79.02 & 79.05 \\
5 & 82.41 & 82.58 \\
6 & 134.89 & 135.22 \\
7 & 146.75 & 146.89 \\
8 & 175.84 & 176.1 \\
9 & 181.77 & 181.9 \\
10 & 271.76 & 271.8 \\
\hline
\end{tabular}

$$
\begin{aligned}
& K_{i i}^{22}=\int_{0}^{l_{i}} E_{i} S_{i} \xi_{u_{i}}^{\prime T}(x) \xi_{u_{i}}^{\prime}(x) d x+k_{(i, 1)}^{x} \xi_{u_{i}}^{T}(0) \xi_{u_{i}}^{\prime}(0) \\
& \quad+k_{(i, 2)}^{x} \xi_{u_{i}}^{T}\left(l_{i}\right) \xi_{u_{i}}^{\prime}\left(l_{i}\right)+\sum_{j=1}^{n}\left(1-\delta_{i j}\right)
\end{aligned}
$$



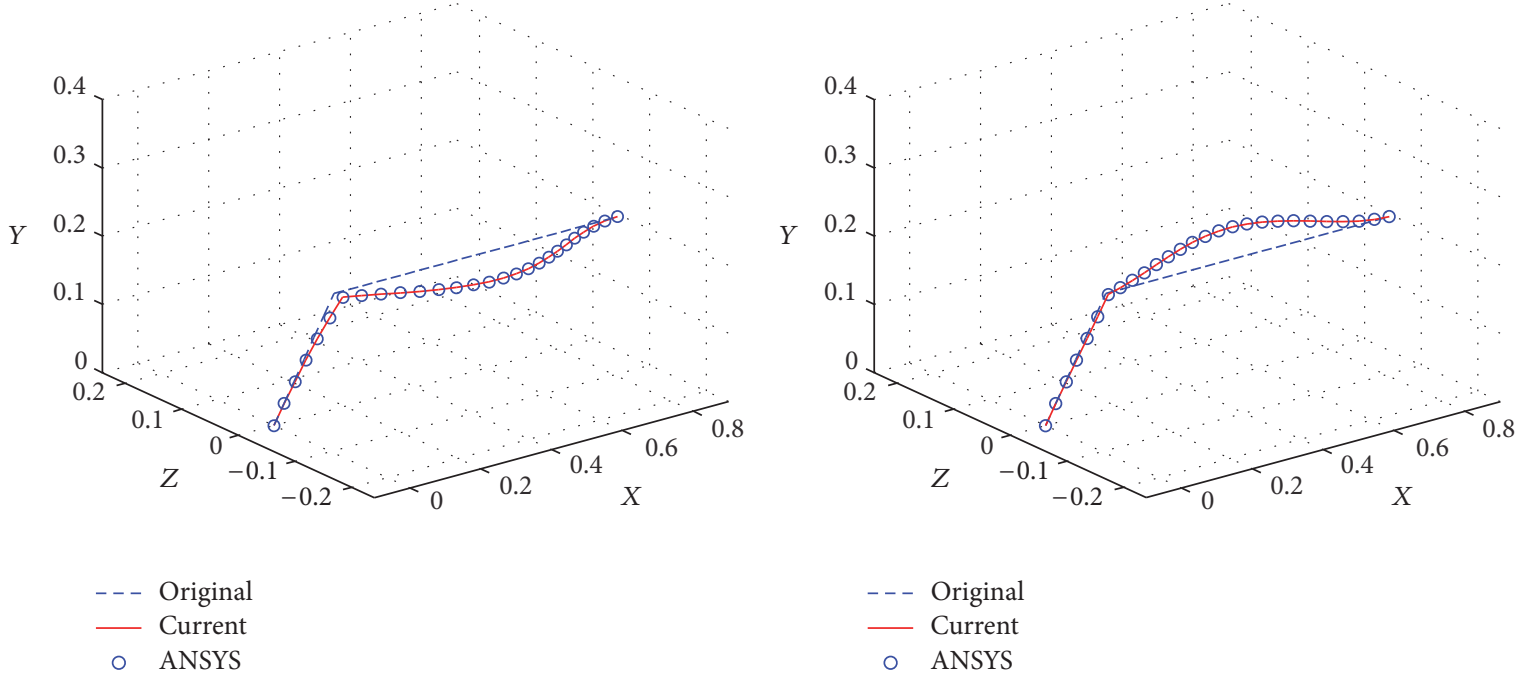

(a)

(b)
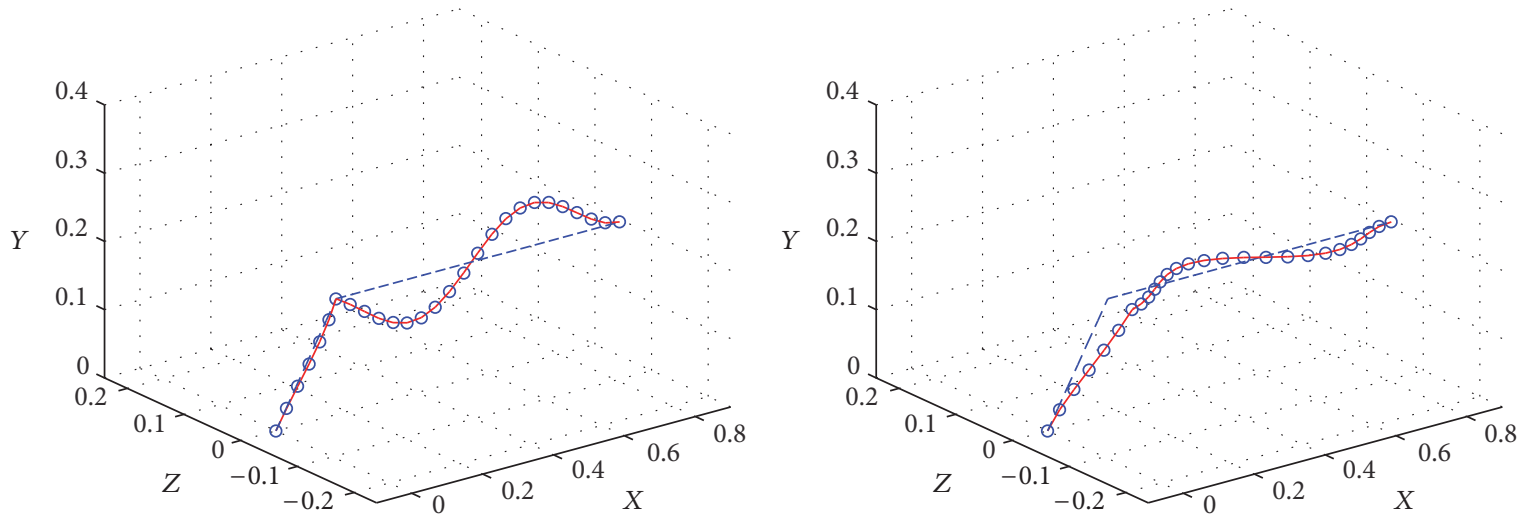

$\begin{array}{cc}--- & \text { Original } \\ - & \text { Current } \\ \circ & \text { ANSYS }\end{array}$

- - - Original

- Current

- ANSYS

(c)

(d)
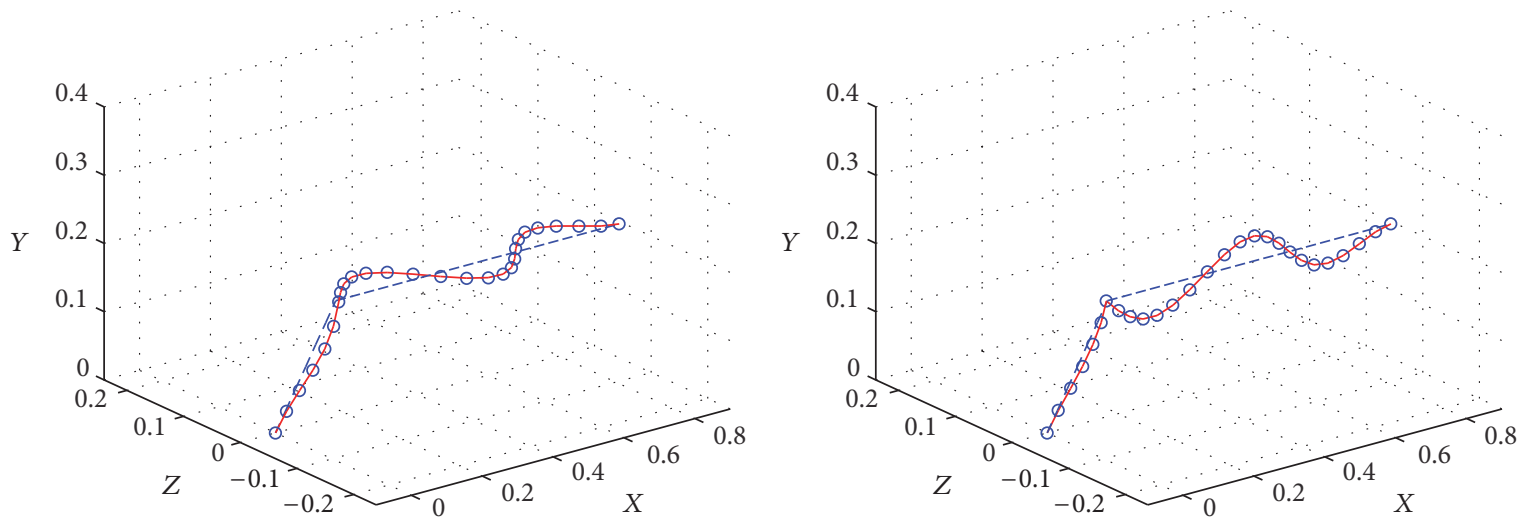

- - - Origina

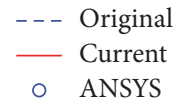

(e)

Figure 6: Continued. 

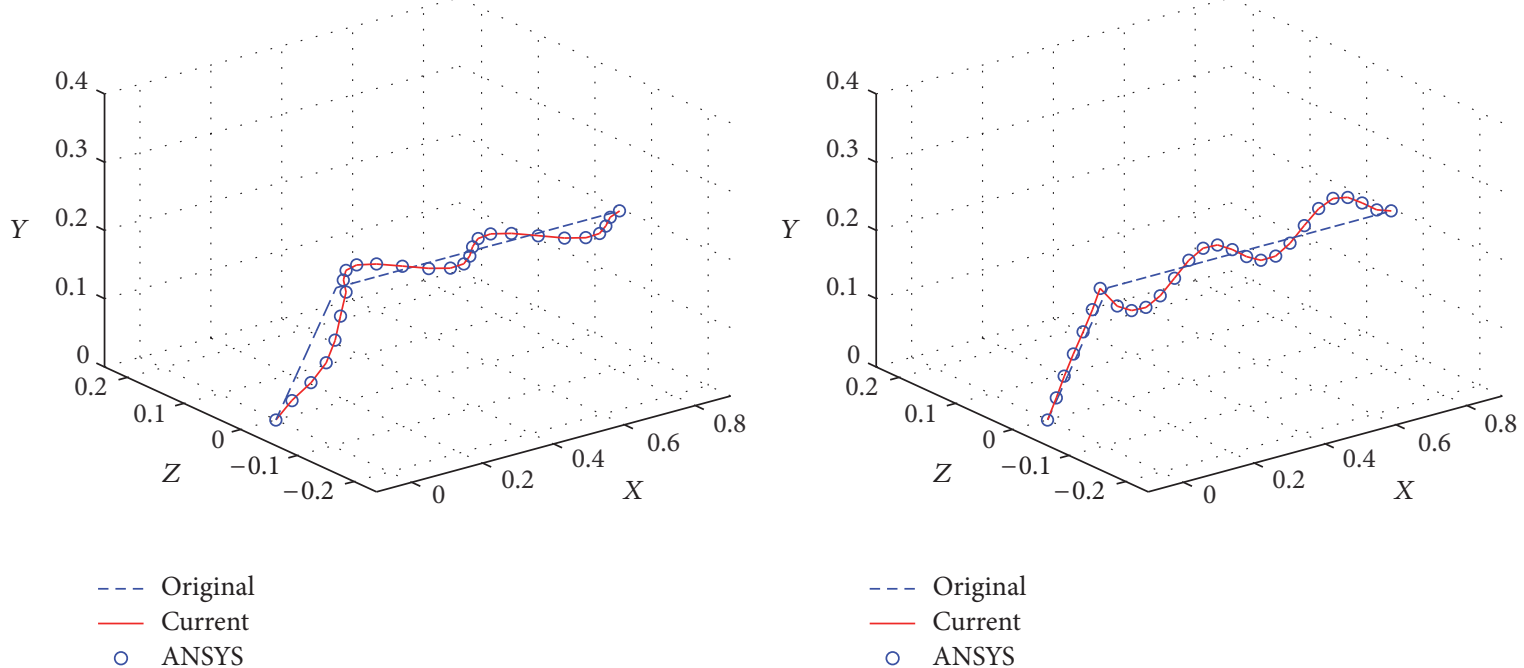

(g)

(h)

FIGURE 6: The first eight modes of coupled beams with $45^{\circ}$ coupling angle: (a) the first mode, (b) the second mode, (c) the third mode, (d) the fourth mode, (e) the fifth mode, (f) the sixth mode, (g) the seventh mode, and (h) the eighth mode.

$$
\begin{aligned}
& \cdot\left(k_{12}^{x} \cos ^{2} \alpha_{i}+k_{12}^{y} \sin ^{2} \alpha_{i}\right)\left[\xi_{u_{i}}^{T}\left(x_{0}\right) \xi_{u_{i}}^{\prime}\left(x_{0}\right)\right], \\
& K_{i i}^{23}=\sum_{j=1}^{n}\left(1-\delta_{i j}\right)\left(-k_{12}^{x}+k_{12}^{y}\right) \sin \alpha_{i} \cos \alpha_{i} \\
& \cdot\left[\xi_{u_{i}}^{T}\left(x_{0}\right) \varphi_{w_{i, y}}^{\prime}\left(x_{0}\right)\right] \text {, } \\
& K_{i i}^{24}=\sum_{j=1}^{n}\left(1-\delta_{i j}\right)\left(-k_{12}^{x}+k_{12}^{y}\right) \sin \alpha_{i} \cos \alpha_{i} \\
& \cdot\left[\xi_{u_{i}}^{T}\left(x_{0}\right) \xi_{w_{i, y}}^{\prime}\left(x_{0}\right)\right] \\
& K_{i i}^{33}=\int_{0}^{l_{i}} E_{i} I_{i} \varphi_{w_{i, y}}^{\prime \prime T}(x) \varphi_{w_{i, y}}^{\prime \prime}(x) d x+k_{(i, 1)}^{y} \varphi_{w_{i, y}}^{T}(0) \\
& \cdot \varphi_{w_{i, y}}(0)+k_{(i, 2)}^{y} \varphi_{w_{i, y}}^{T}\left(l_{i}\right) \varphi_{w_{i, y}}\left(l_{i}\right)+K_{(i, 1)}^{z} \varphi_{w_{i, y}}^{\prime T}(0) \\
& \cdot \varphi_{w_{i, y}}^{\prime}(0)+K_{(i, 2)}^{z} \varphi_{w_{i, y}}^{\prime T}\left(l_{i}\right) \varphi_{w_{i, y}}^{\prime}\left(l_{i}\right)+\sum_{j=1}^{n}\left(1-\delta_{i j}\right) \\
& \cdot\left(k_{12}^{x} \sin ^{2} \alpha_{i}+k_{12}^{y} \cos ^{2} \alpha_{i}\right)\left[\varphi_{w_{i, y}}^{T}\left(x_{0}\right) \varphi_{w_{i, y}}^{\prime}\left(x_{0}\right)\right] \\
& +\sum_{j=1}^{n}\left(1-\delta_{i j}\right) K_{12}^{z} \varphi_{w_{i, y}}^{\prime T}\left(x_{0}\right) \varphi_{w_{i, y}}^{\prime}\left(x_{0}\right), \\
& K_{i i}^{34}=\int_{0}^{l_{i}} E_{i} I_{i} \varphi_{w_{i, y}}^{\prime \prime T}(x) \xi_{w_{i, y}}^{\prime \prime}(x) d x+k_{(i, 1)}^{y} \varphi_{w_{i, y}}^{T}(0) \\
& \cdot \xi_{w_{i, y}}(0)+k_{(i, 2)}^{y} \varphi_{w_{i, y}}^{T}\left(l_{i}\right) \xi_{w_{i, y}}\left(l_{i}\right)+K_{(i, 1)}^{z} \varphi_{w_{i, y}}^{T}(0) \\
& \cdot \xi_{w_{i, y}}^{\prime}(0)+K_{(i, 2)}^{z} \varphi_{w_{i, y}}^{\prime T}\left(l_{i}\right) \xi_{w_{i, y}}^{\prime}\left(l_{i}\right)+\sum_{j=1}^{n}\left(1-\delta_{i j}\right) \\
& \cdot\left(k_{12}^{x} \sin ^{2} \alpha_{i}+k_{12}^{y} \cos ^{2} \alpha_{i}\right)\left[\varphi_{w_{i, y}}^{T}\left(x_{0}\right) \xi_{w_{i, y}}^{\prime}\left(x_{0}\right)\right]
\end{aligned}
$$

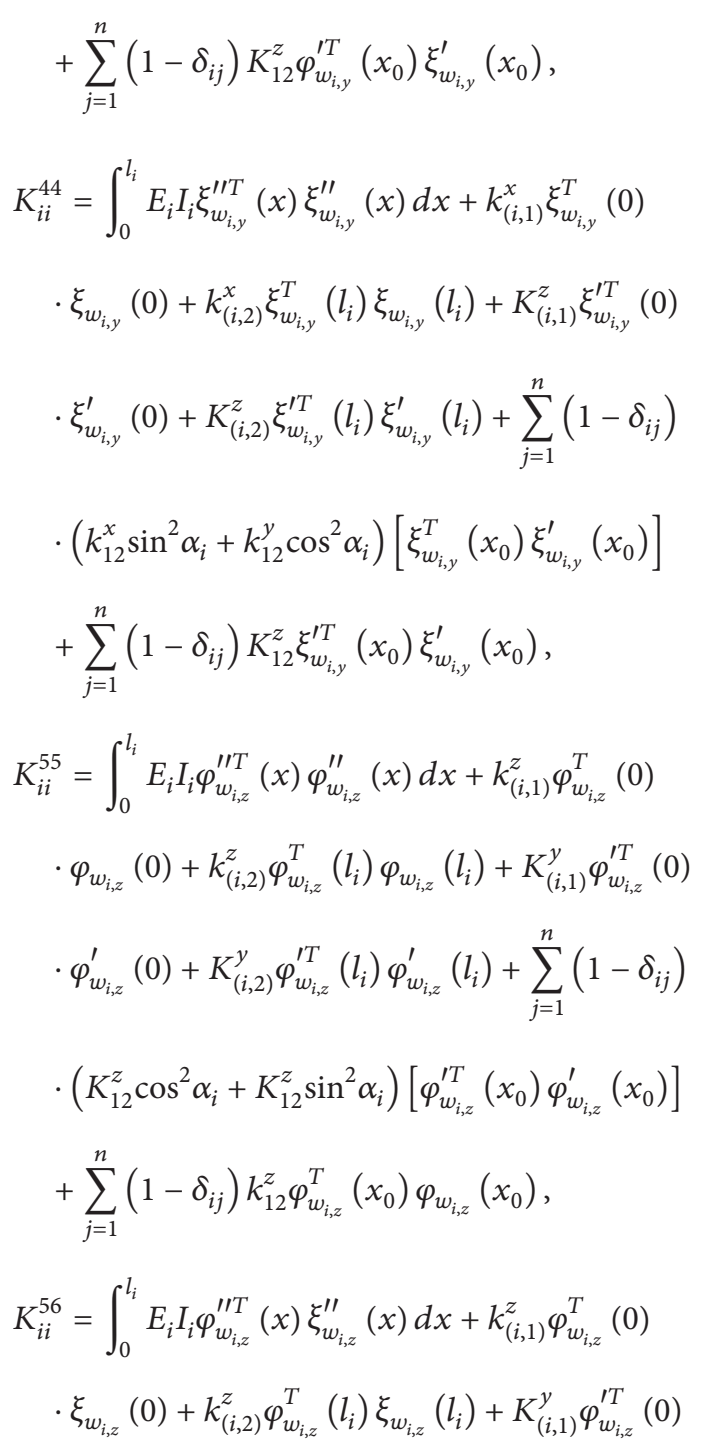




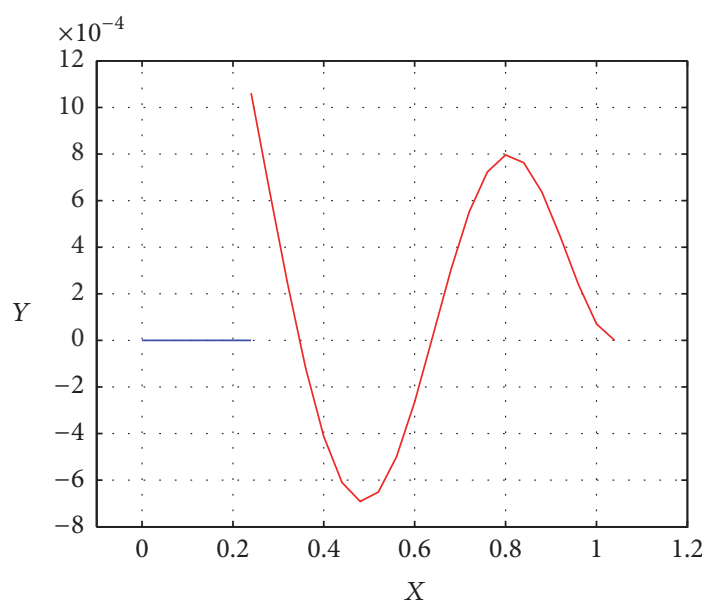

- Beam 1

- Beam 2

(a)

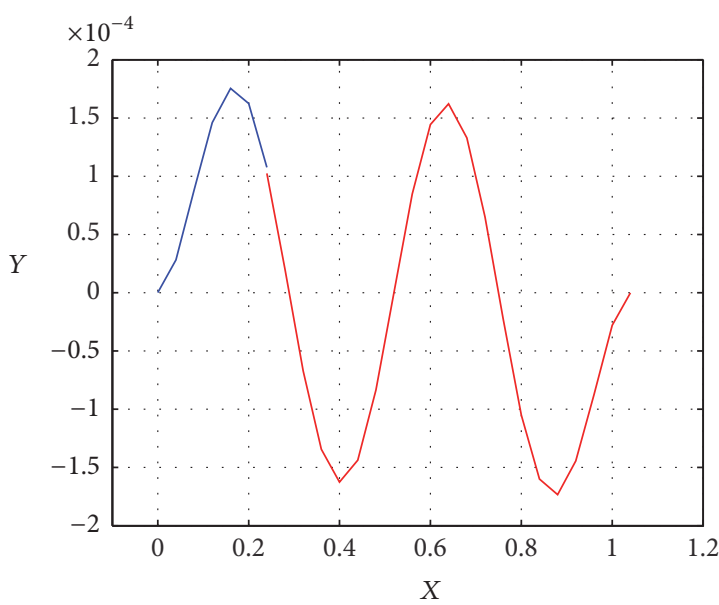

Beam 1

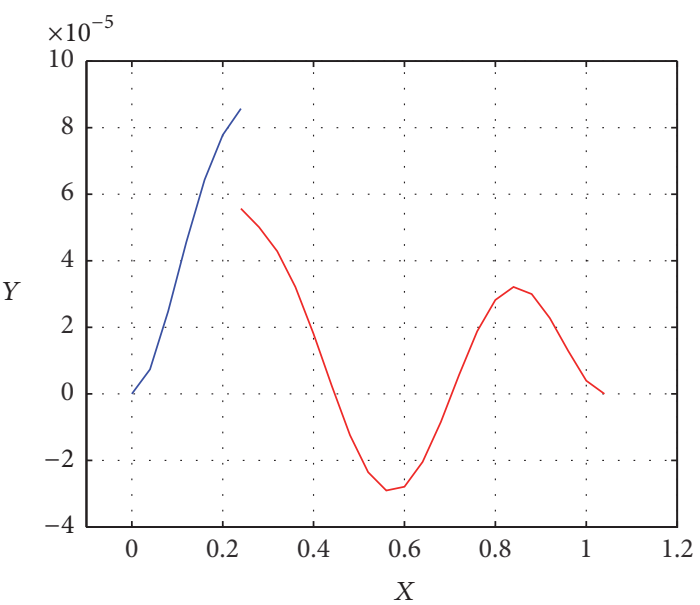

— Beam 1

— Beam 2

(b)

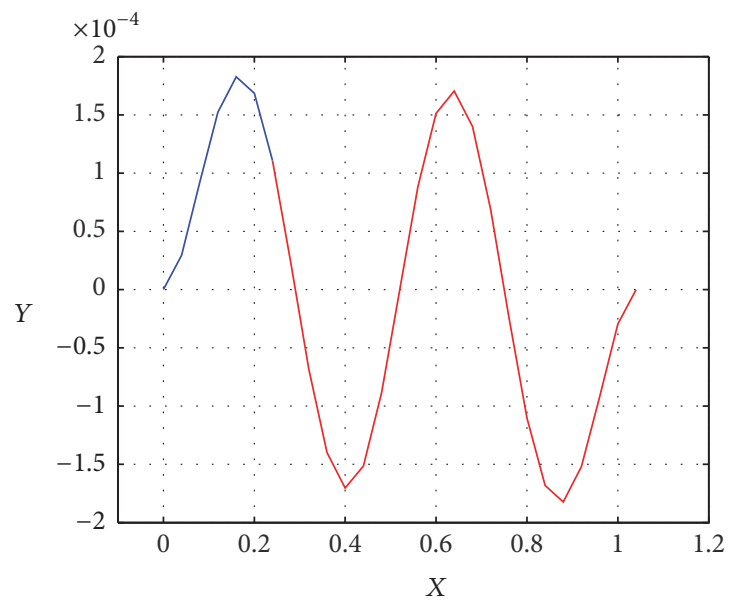

- Beam 1

— Beam 2

(c)

(d)

FIgURE 7: The fourth mode for the coupled beams with the four cases: (a) case 1, (b) case 2, (c) case 3, and (d) case 4.

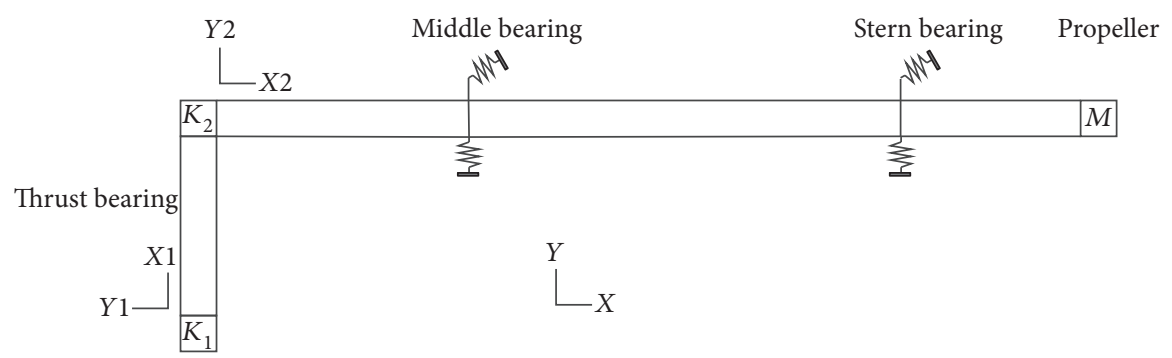

FIGURE 8: The propulsion shafting with multisupport bearings.

$\cdot \xi_{w_{i, z}}^{\prime}(0)+K_{(i, 2)}^{y} \varphi_{w_{i, z}}^{\prime T}\left(l_{i}\right) \xi_{w_{i, z}}^{\prime}\left(l_{i}\right)+\sum_{j=1}^{n}\left(1-\delta_{i j}\right)$

$+\sum_{j=1}^{n}\left(1-\delta_{i j}\right) k_{12}^{z} \varphi_{w_{i, z}}^{T}\left(x_{0}\right) \xi_{w_{i, z}}\left(x_{0}\right)$

$\cdot\left(K_{12}^{z} \cos ^{2} \alpha_{i}+K_{12}^{z} \sin ^{2} \alpha_{i}\right)\left[\varphi_{w_{i, z}}^{\prime T}\left(x_{0}\right) \xi_{w_{i, z}}^{\prime}\left(x_{0}\right)\right]$

$K_{i i}^{57}=\sum_{j=1}^{n}\left(1-\delta_{i j}\right)\left(-k_{12}^{x}+k_{12}^{y}\right) \sin \alpha_{i}$ 

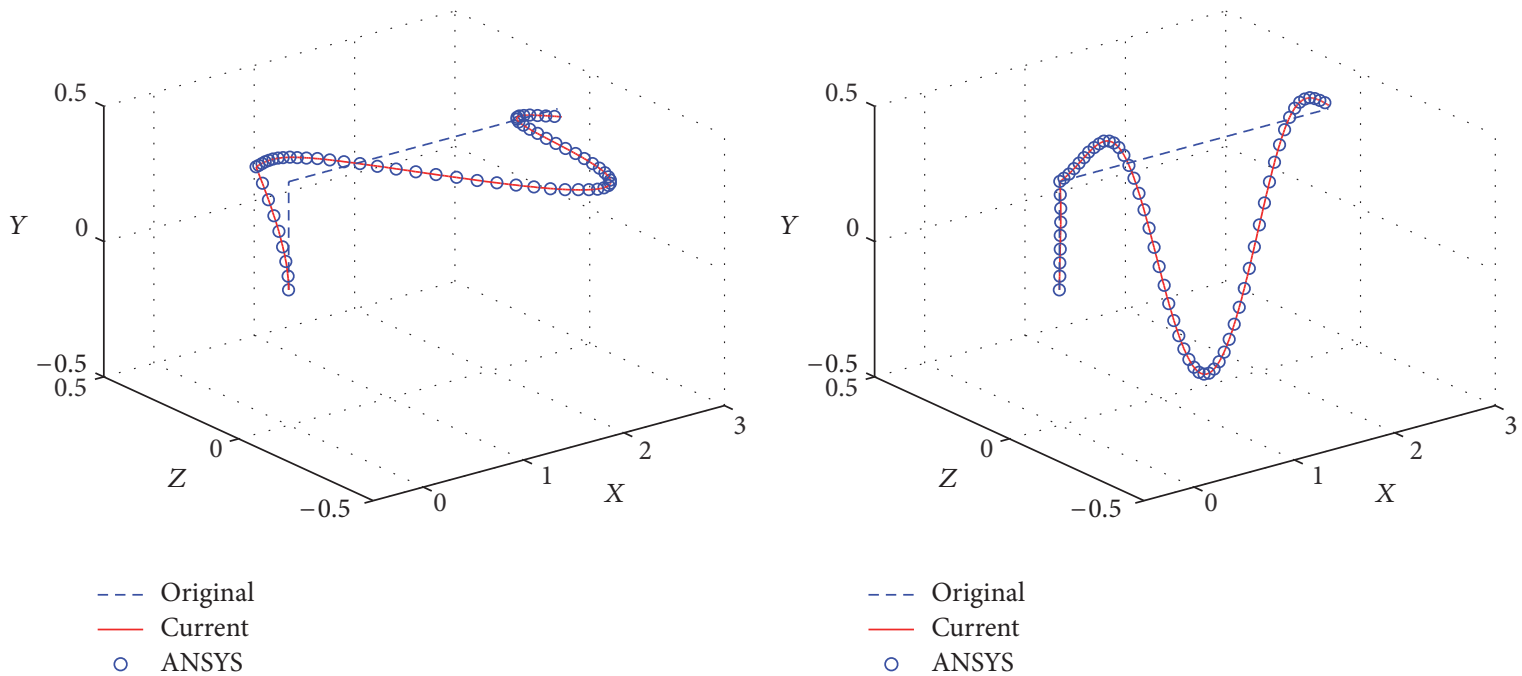

(a)
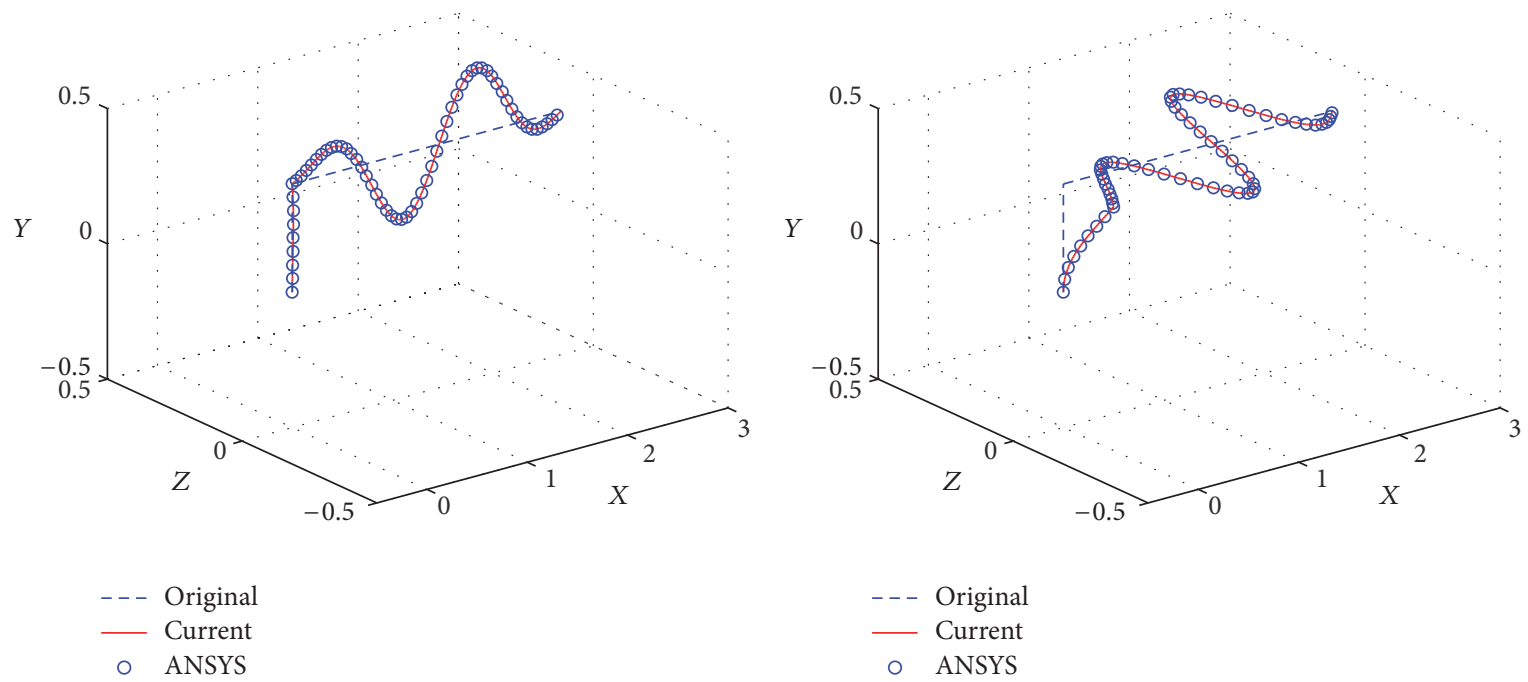

(c)

(d)
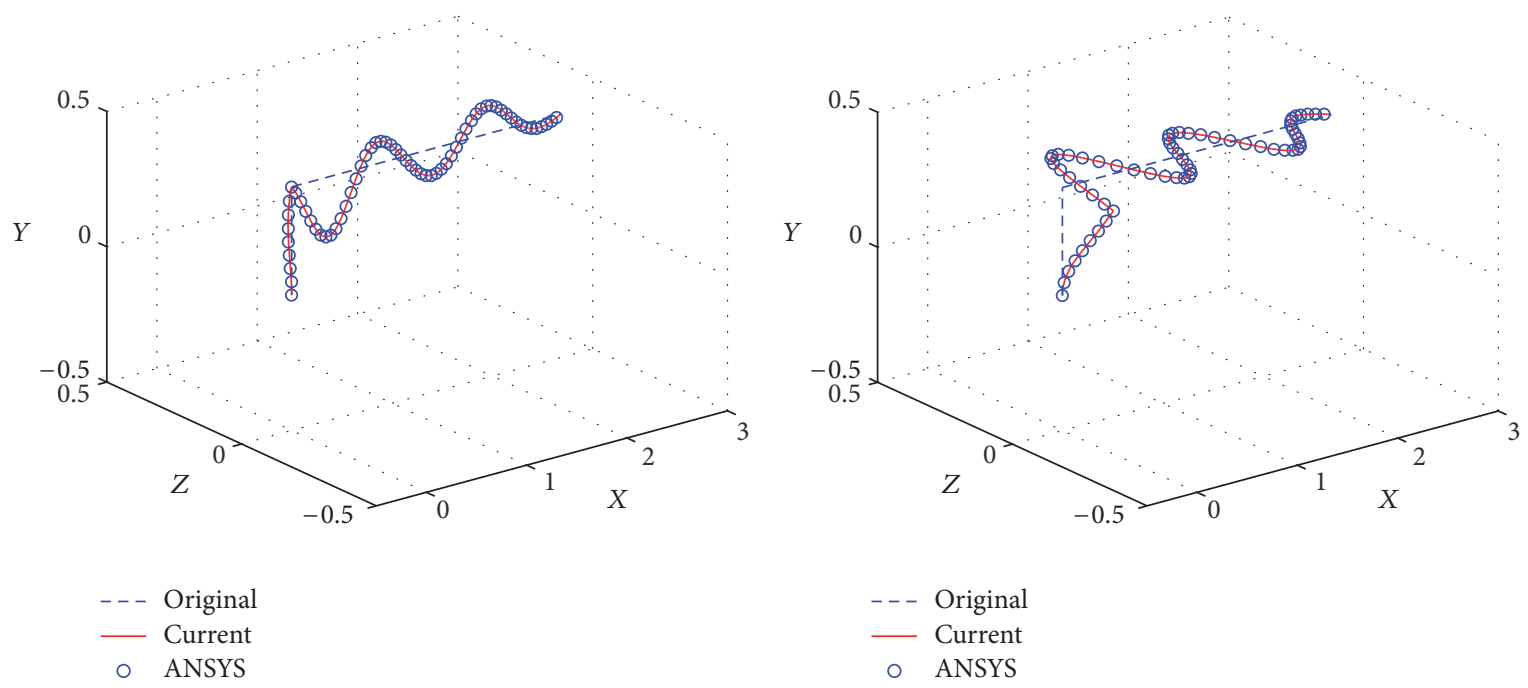

(e)

Figure 9: Continued. 


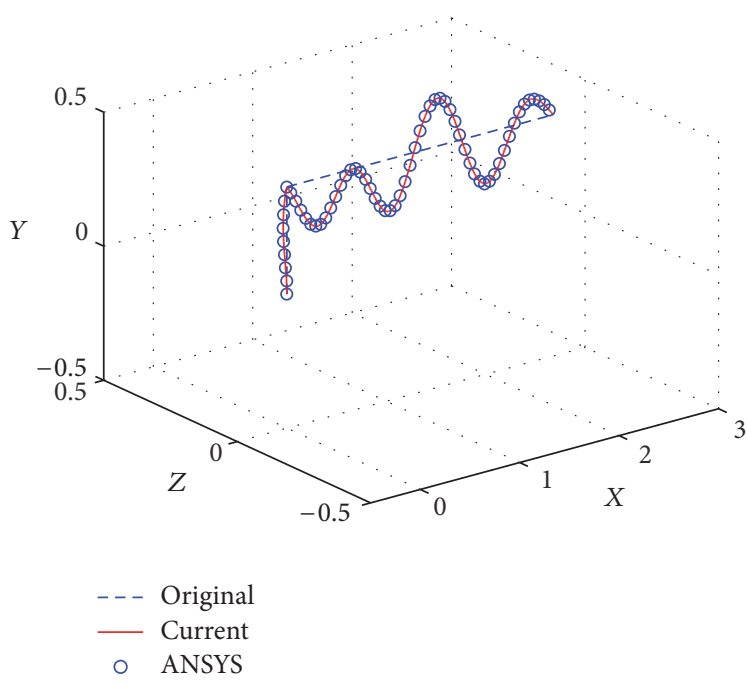

(g)

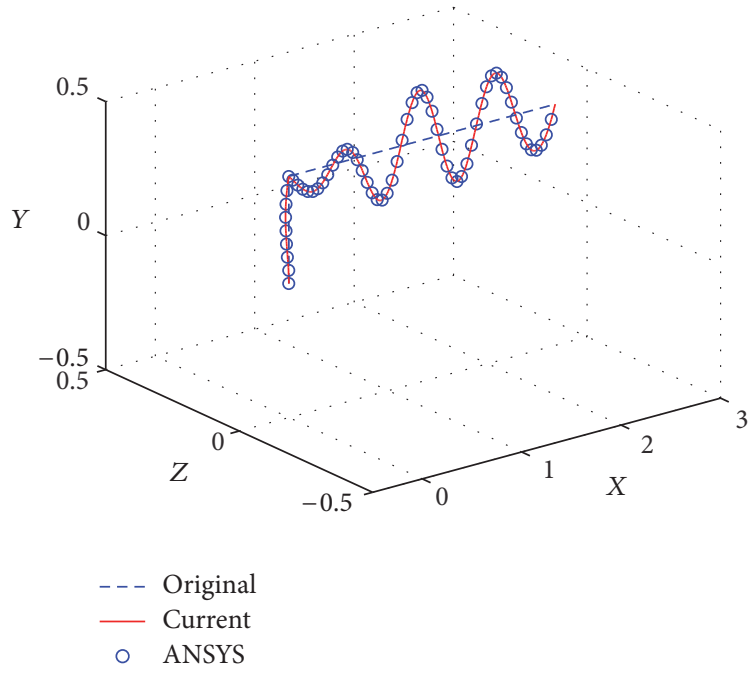

(i)

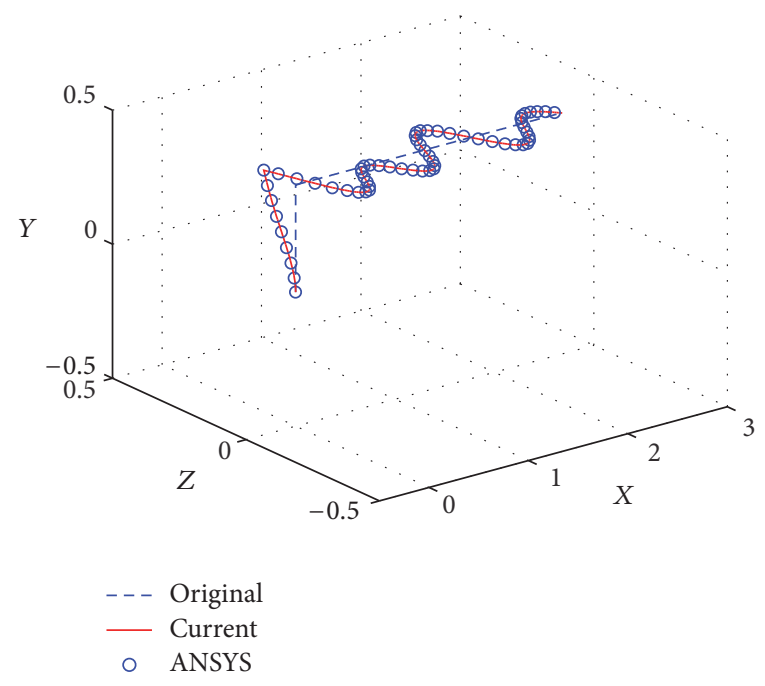

(h)

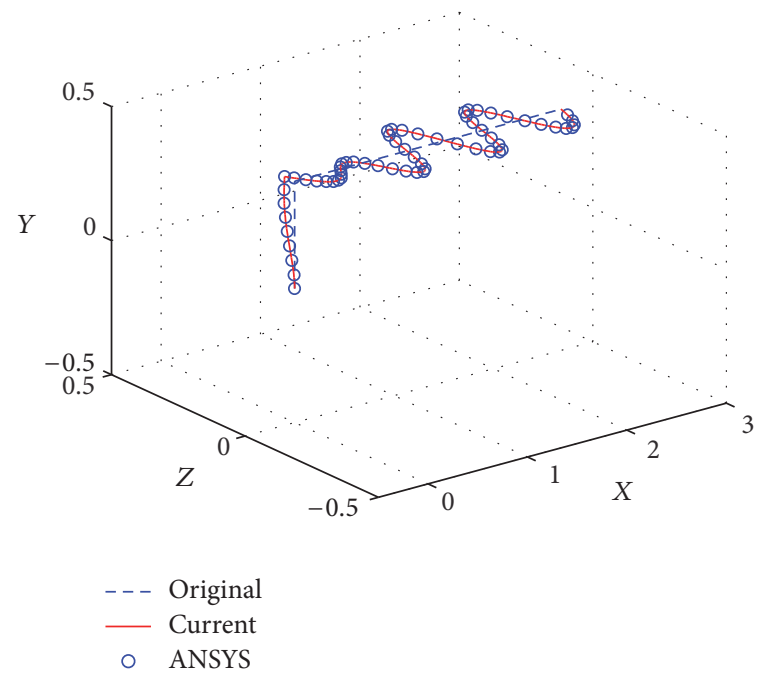

(j)

Figure 9: The first ten modes for the shafting: (a) the first mode, (b) the second mode, (c) the third mode, (d) the fourth mode, (e) the fifth mode, (f) the sixth mode, (g) the seventh mode, (h) the eighth mode, (i) the ninth mode, and (j) the tenth mode.

$$
\begin{array}{cc}
\cdot \cos \alpha_{i}\left[\varphi_{w_{i, z}}^{T T}\left(x_{0}\right) \varphi_{\theta_{i}}^{\prime}\left(x_{0}\right)\right], & +\sum_{j=1}^{n}\left(1-\delta_{i j}\right) k_{12}^{z} \xi_{w_{i, z}}^{T}\left(x_{0}\right) \xi_{w_{i, z}}\left(x_{0}\right), \\
K_{i i}^{58}=\sum_{j=1}^{n}\left(1-\delta_{i j}\right)\left(-k_{12}^{x}+k_{12}^{y}\right) \sin \alpha_{i} & K_{i i}^{67}=\sum_{j=1}^{n}\left(1-\delta_{i j}\right)\left(-k_{12}^{x}+k_{12}^{y}\right) \sin \alpha_{i} \\
\cdot \cos \alpha_{i}\left[\varphi_{w_{i, z}}^{\prime T}\left(x_{0}\right) \xi_{\theta_{i}}^{\prime}\left(x_{0}\right)\right], & \cdot \cos \alpha_{i}\left[\xi_{w_{i, z}}^{T}\left(x_{0}\right) \varphi_{\theta_{i}}^{\prime}\left(x_{0}\right)\right], \\
K_{i i}^{66}=\int_{0}^{l_{i}} E_{i} I_{i} \xi_{w_{i, z}}^{\prime \prime T}(x) \xi_{w_{i, z}}^{\prime \prime}(x) d x+k_{(i, 1)}^{z} \xi_{w_{i, z}}^{T}(0) & K_{i i}^{68}=\sum_{j=1}^{n}\left(1-\delta_{i j}\right)\left(-k_{12}^{x}+k_{12}^{y}\right) \sin \alpha_{i} \\
\cdot \xi_{w_{i, z}}(0)+k_{(i, 2)}^{z} \xi_{w_{i, z}}^{T}\left(l_{i}\right) \xi_{w_{i, z}}\left(l_{i}\right)+K_{(i, 1)}^{y} \xi_{w_{i, z}}^{T}(0) & \cdot \cos \alpha_{i}\left[\xi_{w_{i, z}^{\prime T}}^{\prime T}\left(x_{0}\right) \xi_{\theta_{i}}^{\prime}\left(x_{0}\right)\right], \\
\cdot \xi_{w_{i, z}}^{\prime}(0)+K_{(i, 2)}^{y} \xi_{w_{i, z}^{\prime T}}\left(l_{i}\right) \xi_{w_{i, z}}^{\prime}\left(l_{i}\right)+\sum_{j=1}^{n}\left(1-\delta_{i j}\right) & K_{i i}^{77}=\int_{0}^{l_{i}} G_{i} J_{i} \varphi_{\theta_{i}}^{\prime T}(x) \varphi_{\theta_{i}}^{\prime}(x) d x+K_{(i, 1)}^{x} \varphi_{\theta_{i}}^{T}(0) \varphi_{\theta_{i}}^{\prime}(0) \\
\cdot\left(K_{12}^{z} \cos ^{2} \alpha_{i}+K_{12}^{z} \sin ^{2} \alpha_{i}\right)\left[\xi_{w_{i, z}}^{\prime T}\left(x_{0}\right) \xi_{w_{i, z}}^{\prime}\left(x_{0}\right)\right] &
\end{array}
$$




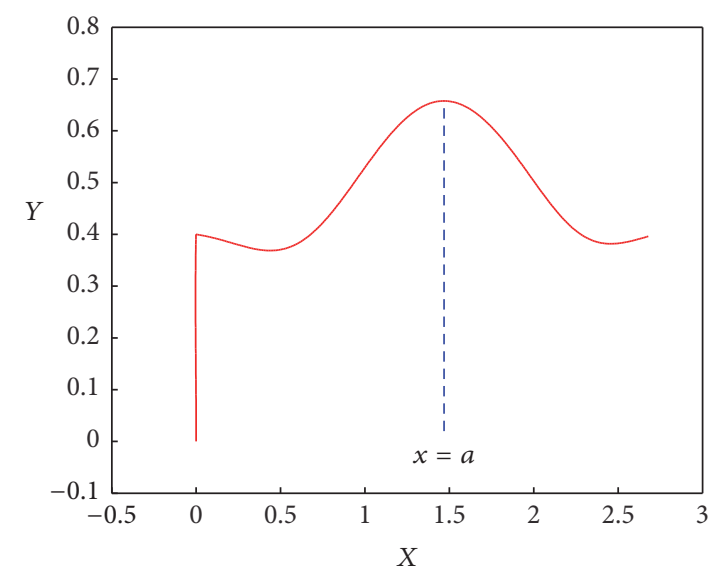

(a) The first lateral vibration mode $f_{a}=27.93 \mathrm{~Hz}$

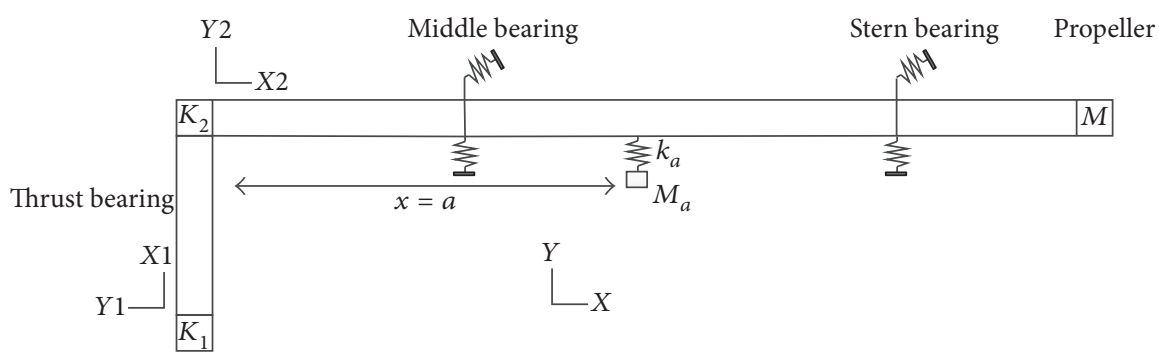

(b) The model of the shafting with the absorber

FIgURE 10: The calculated mode with absorber.

$$
\begin{aligned}
&+ K_{(i, 2)}^{x} \varphi_{\theta_{i}}^{T}\left(l_{i}\right) \varphi_{\theta_{i}}^{\prime}\left(l_{i}\right)+\sum_{j=1}^{n}\left(1-\delta_{i j}\right) \\
& \cdot\left(K_{12}^{x} \cos ^{2} \alpha_{i}+K_{12}^{y} \sin ^{2} \alpha_{i}\right)\left[\varphi_{\theta_{i}}^{\prime T}\left(x_{0}\right) \varphi_{\theta_{i}}^{\prime}\left(x_{0}\right)\right], \\
& K_{i i}^{78}=\int_{0}^{l_{i}} G_{i} J_{i} \varphi_{\theta_{i}}^{\prime T}(x) \xi_{\theta_{i}}^{\prime}(x) d x+K_{(i, 1)}^{x} \varphi_{\theta_{i}}^{T}(0) \xi_{\theta_{i}}^{\prime}(0) \\
&+K_{(i, 2)}^{x} \varphi_{\theta_{i}}^{T}\left(l_{i}\right) \xi_{\theta_{i}}^{\prime}\left(l_{i}\right)+\sum_{j=1}^{n}\left(1-\delta_{i j}\right) \\
& \cdot\left(K_{12}^{x} \cos ^{2} \alpha_{i}+K_{12}^{y} \sin ^{2} \alpha_{i}\right)\left[\varphi_{\theta_{i}}^{\prime T}\left(x_{0}\right) \xi_{\theta_{i}}^{\prime}\left(x_{0}\right)\right], \\
& K_{i i}^{88}=\int_{0}^{l_{i}} G_{i} J_{i} \xi_{\theta_{i}}^{\prime T}(x) \xi_{\theta_{i}}^{\prime}(x) d x+K_{(i, 1)}^{x} \xi_{\theta_{i}}^{T}(0) \xi_{\theta_{i}}^{\prime}(0) \\
&+K_{(i, 2)}^{x} \xi_{\theta_{i}}^{T}\left(l_{i}\right) \xi_{\theta_{i}}^{\prime}\left(l_{i}\right)+\sum_{j=1}^{n}\left(1-\delta_{i j}\right) \\
& \cdot\left(K_{12}^{x} \cos \alpha_{i}+K_{12}^{y} \sin ^{2} \alpha_{i}\right)\left[\xi_{\theta_{i}}^{\prime T}\left(x_{0}\right) \xi_{\theta_{i}}^{\prime}\left(x_{0}\right)\right], \\
& K_{i j}^{11}=\left(k_{12}^{x} \cos \alpha_{i} \cos \alpha_{j}+k_{12}^{y} \sin \alpha_{i} \sin \alpha_{j}\right)\left[\varphi_{u_{i}}^{T}\left(l_{i}\right)\right. \\
&\left.\cdot \varphi_{u_{i}}(0)\right], \\
& K_{i j}^{12}=\left(k_{12}^{x} \cos \alpha_{i} \cos \alpha_{j}+k_{12}^{y} \sin \alpha_{i} \sin \alpha_{j}\right)\left[\varphi_{u_{i}}^{T}\left(l_{i}\right)\right. \\
&\left.\cdot \xi_{u_{i}}(0)\right],
\end{aligned}
$$

$$
\begin{aligned}
& K_{i j}^{13}=\left(-k_{12}^{x} \cos \alpha_{i} \sin \alpha_{j}+k_{12}^{y} \sin \alpha_{i} \cos \alpha_{j}\right)\left[\varphi_{u_{i}}^{T}\left(l_{i}\right)\right. \\
& \left.\cdot \varphi_{w_{j, y}}(0)\right], \\
& K_{i j}^{14}=\left(-k_{12}^{x} \cos \alpha_{i} \sin \alpha_{j}+k_{12}^{y} \sin \alpha_{i} \cos \alpha_{j}\right)\left[\varphi_{u_{i}}^{T}\left(l_{i}\right)\right. \\
& \left.\cdot \xi_{w_{j, y}}(0)\right], \\
& K_{i j}^{22}=\left(k_{12}^{x} \cos \alpha_{i} \cos \alpha_{j}+k_{12}^{y} \sin \alpha_{i} \sin \alpha_{j}\right)\left[\xi_{u_{i}}^{T}\left(l_{i}\right)\right. \\
& \left.\cdot \xi_{u_{i}}(0)\right], \\
& K_{i j}^{23}=\left(-k_{12}^{x} \cos \alpha_{i} \sin \alpha_{j}+k_{12}^{y} \sin \alpha_{i} \cos \alpha_{j}\right)\left[\xi_{u_{i}}^{T}\left(l_{i}\right)\right. \\
& \left.\cdot \varphi_{w_{j, y}}(0)\right], \\
& K_{i j}^{24}=\left(-k_{12}^{x} \cos \alpha_{i} \sin \alpha_{j}+k_{12}^{y} \sin \alpha_{i} \cos \alpha_{j}\right)\left[\xi_{u_{i}}^{T}\left(l_{i}\right)\right. \\
& \left.\cdot \xi_{w_{j, y}}(0)\right], \\
& K_{i j}^{31}=\left(-k_{12}^{x} \sin \alpha_{i} \sin \alpha_{j}+k_{12}^{y} \cos \alpha_{i} \sin \alpha_{j}\right) \\
& \cdot\left[\varphi_{w_{j, y}}^{T}\left(l_{i}\right) \varphi_{u_{i}}(0)\right], \\
& K_{i j}^{32}=\left(-k_{12}^{x} \sin \alpha_{i} \sin \alpha_{j}+k_{12}^{y} \cos \alpha_{i} \sin \alpha_{j}\right) \\
& \cdot\left[\varphi_{w_{j, y}}^{T}\left(l_{i}\right) \xi_{u_{i}}(0)\right], \\
&
\end{aligned}
$$




$$
\begin{aligned}
& K_{i j}^{33}=\left(-k_{12}^{x} \sin \alpha_{i} \sin \alpha_{j}+k_{12}^{y} \cos \alpha_{i} \sin \alpha_{j}\right) \\
& K_{i j}^{32}=\left(-k_{12}^{x} \sin \alpha_{i} \sin \alpha_{j}+k_{12}^{y} \cos \alpha_{i} \sin \alpha_{j}\right)\left[\varphi_{\theta_{i}}^{T}\left(l_{i}\right)\right. \\
& \cdot\left[\varphi_{w_{j, y}}^{T}\left(l_{i}\right) \varphi_{w_{j, y}}(0)\right], \\
& K_{i j}^{34}=\left(-k_{12}^{x} \sin \alpha_{i} \sin \alpha_{j}+k_{12}^{y} \cos \alpha_{i} \sin \alpha_{j}\right) \\
& \cdot\left[\varphi_{w_{j, y}}^{T}\left(l_{i}\right) \xi_{w_{j, y}}(0)\right], \\
& K_{i j}^{41}=\left(-k_{12}^{x} \sin \alpha_{i} \sin \alpha_{j}+k_{12}^{y} \cos \alpha_{i} \sin \alpha_{j}\right) \\
& \cdot\left[\xi_{w_{j, y}}^{T}\left(l_{i}\right) \varphi_{u_{i}}(0)\right] \\
& K_{i j}^{42}=\left(-k_{12}^{x} \sin \alpha_{i} \sin \alpha_{j}+k_{12}^{y} \cos \alpha_{i} \sin \alpha_{j}\right) \\
& \cdot\left[\xi_{w_{j, y}}^{T}\left(l_{i}\right) \xi_{u_{i}}(0)\right] \\
& K_{i j}^{43}=\left(-k_{12}^{x} \sin \alpha_{i} \sin \alpha_{j}+k_{12}^{y} \cos \alpha_{i} \sin \alpha_{j}\right) \\
& \cdot\left[\xi_{w_{j, y}}^{T}\left(l_{i}\right) \varphi_{w_{j, y}}(0)\right] \\
& K_{i j}^{44}=\left(-k_{12}^{x} \sin \alpha_{i} \sin \alpha_{j}+k_{12}^{y} \cos \alpha_{i} \sin \alpha_{j}\right) \\
& \cdot\left[\xi_{w_{j, y}}^{T}\left(l_{i}\right) \xi_{w_{j, y}}(0)\right] \\
& K_{i j}^{55}=\left(k_{12}^{x} \cos \alpha_{i} \cos \alpha_{j}+k_{12}^{y} \sin \alpha_{i} \sin \alpha_{j}\right)\left[\varphi_{w_{i, z}}^{T}\left(l_{i}\right)\right. \\
& \left.\cdot \varphi_{w_{i, z}}(0)\right] \text {, } \\
& K_{i j}^{56}=\left(k_{12}^{x} \cos \alpha_{i} \cos \alpha_{j}+k_{12}^{y} \sin \alpha_{i} \sin \alpha_{j}\right)\left[\varphi_{w_{i, z}}^{T}\left(l_{i}\right)\right. \\
& \left.\cdot \xi_{u_{i}}(0)\right] \\
& K_{i j}^{57}=\left(-k_{12}^{x} \cos \alpha_{i} \sin \alpha_{j}+k_{12}^{y} \sin \alpha_{i} \cos \alpha_{j}\right) \\
& \cdot\left[\varphi_{w_{i, z}}^{T}\left(l_{i}\right) \varphi_{\theta_{j}}(0)\right], \\
& K_{i j}^{58}=\left(-k_{12}^{x} \cos \alpha_{i} \sin \alpha_{j}+k_{12}^{y} \sin \alpha_{i} \cos \alpha_{j}\right) \\
& \cdot\left[\varphi_{w_{i, z}}^{T}\left(l_{i}\right) \xi_{\theta_{j}}(0)\right], \\
& K_{i j}^{66}=\left(k_{12}^{x} \cos \alpha_{i} \cos \alpha_{j}+k_{12}^{y} \sin \alpha_{i} \sin \alpha_{j}\right)\left[\xi_{w_{i, z}}^{T}\left(l_{i}\right)\right. \\
& \left.\cdot \xi_{u_{i}}(0)\right] \\
& K_{i j}^{67}=\left(-k_{12}^{x} \cos \alpha_{i} \sin \alpha_{j}+k_{12}^{y} \sin \alpha_{i} \cos \alpha_{j}\right) \\
& \cdot\left[\xi_{w_{i, z}}^{T}\left(l_{i}\right) \varphi_{w_{j, y}}(0)\right] \\
& K_{i j}^{24}=\left(-k_{12}^{x} \cos \alpha_{i} \sin \alpha_{j}+k_{12}^{y} \sin \alpha_{i} \cos \alpha_{j}\right) \\
& \cdot\left[\xi_{w_{i, z}}^{T}\left(l_{i}\right) \xi_{\theta_{j}}(0)\right], \\
& K_{i j}^{31}=\left(-k_{12}^{x} \sin \alpha_{i} \sin \alpha_{j}+k_{12}^{y} \cos \alpha_{i} \sin \alpha_{j}\right)\left[\varphi_{\theta_{i}}^{T}\left(l_{i}\right)\right. \\
& \left.\cdot \varphi_{w_{i, z}}(0)\right] \\
& \left.\cdot \xi_{w_{i, z}}(0)\right] \\
& K_{i j}^{33}=\left(-k_{12}^{x} \sin \alpha_{i} \sin \alpha_{j}+k_{12}^{y} \cos \alpha_{i} \sin \alpha_{j}\right)\left[\varphi_{\theta_{i}}^{T}\left(l_{i}\right)\right. \\
& \left.\cdot \varphi_{\theta_{i}}(0)\right] \text {, } \\
& K_{i j}^{34}=\left(-k_{12}^{x} \sin \alpha_{i} \sin \alpha_{j}+k_{12}^{y} \cos \alpha_{i} \sin \alpha_{j}\right) \\
& \cdot\left[\varphi_{w_{j, y}}^{T}\left(l_{i}\right) \xi_{w_{j, y}}(0)\right], \\
& K_{i j}^{41}=\left(-k_{12}^{x} \sin \alpha_{i} \sin \alpha_{j}+k_{12}^{y} \cos \alpha_{i} \sin \alpha_{j}\right) \\
& \cdot\left[\xi_{w_{j, y}}^{T}\left(l_{i}\right) \varphi_{w_{i, z}}(0)\right], \\
& K_{i j}^{42}=\left(-k_{12}^{x} \sin \alpha_{i} \sin \alpha_{j}+k_{12}^{y} \cos \alpha_{i} \sin \alpha_{j}\right) \\
& \cdot\left[\xi_{w_{j, y}}^{T}\left(l_{i}\right) \xi_{w_{i, z}}(0)\right], \\
& K_{i j}^{43}=\left(-k_{12}^{x} \sin \alpha_{i} \sin \alpha_{j}+k_{12}^{y} \cos \alpha_{i} \sin \alpha_{j}\right) \\
& \cdot\left[\xi_{w_{j, y}}^{T}\left(l_{i}\right) \varphi_{w_{j, y}}(0)\right], \\
& K_{i j}^{44}=\left(-k_{12}^{x} \sin \alpha_{i} \sin \alpha_{j}+k_{12}^{y} \cos \alpha_{i} \sin \alpha_{j}\right) \\
& \cdot\left[\xi_{w_{j, y}}^{T}\left(l_{i}\right) \xi_{w_{j, y}}(0)\right] . \\
& \text { B. Mass Matrices } \\
& \mathbf{M}_{i}^{11}=\int_{0}^{l_{i}} \rho_{i} S_{i} \varphi_{u_{i}}^{T}(x) \varphi_{u_{i}}(x) d x, \\
& \mathbf{M}_{i}^{12}=\int_{0}^{l_{i}} \rho_{i} S_{i} \varphi_{u_{i}}^{T}(x) \xi_{u_{i}}(x) d x \\
& \mathbf{M}_{i}^{22}=\int_{0}^{l_{i}} \rho_{i} S_{i} \xi_{u_{i}}^{T}(x) \xi_{u_{i}}(x) d x, \\
& \mathbf{M}_{i}^{33}=\int_{0}^{l_{i}} \rho_{i} S_{i} \varphi_{w_{i, y}}^{T}(x) \varphi_{w_{i, y}}(x) d x, \\
& \mathbf{M}_{i}^{34}=\int_{0}^{l_{i}} \rho_{i} S_{i} \varphi_{w_{i, y}}^{T}(x) \xi_{w_{i, y}}(x) d x, \\
& \mathbf{M}_{i}^{44}=\int_{0}^{l_{i}} \rho_{i} S_{i} \xi_{w_{i, y}^{T}}^{T}(x) \xi_{w_{i, y}}(x) d x, \\
& \mathbf{M}_{i}^{55}=\int_{0}^{l_{i}} \rho_{i} S_{i} \varphi_{w_{i, z}}^{T}(x) \varphi_{w_{i, z}}(x) d x, \\
& \mathbf{M}_{i}^{56}=\int_{0}^{l_{i}} \rho_{i} S_{i} \varphi_{w_{i, z}}^{T}(x) \xi_{w_{i, z}}(x) d x,
\end{aligned}
$$




$$
\begin{aligned}
& \mathbf{M}_{i}^{66}=\int_{0}^{l_{i}} \rho_{i} S_{i} \xi_{w_{i, z}}^{T}(x) \xi_{w_{i, z}}(x) d x, \\
& \mathbf{M}_{i}^{77}=\int_{0}^{l_{i}} \rho_{i} S_{i} \varphi_{\theta_{i}}^{T}(x) \varphi_{\theta_{i}}(x) d x, \\
& \mathbf{M}_{i}^{78}=\int_{0}^{l_{i}} \rho_{i} S_{i} \varphi_{\theta_{i}}^{T}(x) \xi_{\theta_{i}}(x) d x, \\
& \mathbf{M}_{i}^{88}=\int_{0}^{l_{i}} \rho_{i} S_{i} \xi_{\theta_{i}}^{T}(x) \xi_{\theta_{i}}(x) d x .
\end{aligned}
$$

\section{Nomenclature}

$\begin{array}{ll}L: & \text { Length of beam } \\ \rho_{i}: & \text { Mass density } \\ S_{i}: & \text { Cross-sectional area } \\ J: & \text { Rotational inertia moment } \\ E_{i}: & \text { Young's modulus } \\ I_{i}: & \text { Inertia moment about } z \\ \lambda_{i m}: & \left(\lambda_{i m}=m \pi / l_{i}, 0 \leq x \leq l_{i}, m=0,1,2, \ldots\right) \\ K: & \text { Stiffness matrix } \\ M: & \text { Mass matrix } \\ \alpha_{i}: & \text { The angle between the local and global } \\ \theta_{i, j}: & \quad \text { coordinate system of the beam } i \\ \theta_{i, j}=\left|\alpha_{i}-\alpha_{j}\right|, \text { the coupling angle between } \\ \text { C, S, F: } & \text { Clampe adjacent beams }\end{array}$

\section{Competing Interests}

The authors declare that there is no conflict of interests regarding the publication of this paper.

\section{Acknowledgments}

The research is supported by the National Natural Science Foundation of China (no. 50909023). Their financial support is gratefully acknowledged.

\section{References}

[1] G. B. Zhang and Y. Zhao, "Reduced-order modeling method for longitudinal vibration control of propulsion shafting," IERI Procedia, vol. 1, no. 1, pp. 73-80, 2012.

[2] G. B. Zhang and Y. Zhao, "Propeller excitation of longitudinal vibration characteristics of marine propulsion shafting system," Shock \& Vibration, vol. 2014, Article ID 413592, 19 pages, 2014.

[3] D. Zou, L. Liu, and Z. Rao, "Coupled longitudinal-transverse dynamics of a marine propulsion shafting under primary and internal resonances," Journal of Sound \& Vibration, vol. 372, pp. 299-316, 2016.

[4] Q. Huang, J. Liu, and C. Zhang, "Analysis on propulsion shafting coupled torsional-longitudinal vibration under different applied loads," 2014.

[5] X. Zhou, L. Qin, and Y. P. Xiong, "Vibrational characteristics of a marine shaft coupling system excited by propellor force," in Proceedings of the 21st International Congress on Sound and Vibration (ICSV '14), Beijing, China, July 2014.

[6] C. Li, X. Huang, and H. Hua, "Dynamic modeling and analysis of axial vibration of a coupled propeller and shaft system," Journal of Mechanical Science and Technology, vol. 30, no. 7, pp. 2953-2960, 2016.

[7] J. R. Kane and R. T. McGoldrick, "Longitudinal vibrations of marine propulsion shafting systems," Transactions of the Society of Naval Architects and Marine Engineers, vol. 57, pp. 193-252, 1949.

[8] J. Pan, N. Farag, T. Lin, and R. Juniper, "Propeller induced structural vibration through the thrust bearing," in Proceedings of Meetings on Acoustics, pp. 390-399, November 2002.

[9] R. E. Bishop and D. C. Johnson, The Mechanics of Vibration, Cambridge University Press, Cambridge, Uk, 1960.

[10] N. H. Farag and J. Pan, "Dynamic response and power flow in three-dimensional coupled beam structures. I. Analytical modeling," Journal of the Acoustical Society of America, vol. 102, no. 1, pp. 315-325, 1997.

[11] H. P. Lee, "Transverse vibration of a Timoshenko beam acted on by an accelerating mass," Applied Acoustics, vol. 47, no. 4, pp. 319-330, 1996.

[12] J.-S. Wu and T.-F. Hsu, "Free vibration analyses of simply supported beams carrying multiple point masses and springmass systems with mass of each helical spring considered," International Journal of Mechanical Sciences, vol. 49, no. 7, pp. 834-852, 2007.

[13] W. L. Li, "Free vibrations of beams with general boundary conditions," Journal of Sound and Vibration, vol. 237, no. 4, pp. 709$725,2000$.

[14] W. L. Li and H. Xu, "An exact fourier series method for the vibration analysis of multispan beam systems," Journal of Computational and Nonlinear Dynamics, vol. 4, no. 2, Article ID 021001, 2009.

[15] H. Xu and W. L. Li, "Dynamic behavior of multi-span bridges under moving loads with focusing on the effect of the coupling conditions between spans," Journal of Sound and Vibration, vol. 312, no. 4-5, pp. 736-753, 2008.

[16] W. L. Li, M. W. Bonilha, and J. Xiao, "Vibrations of two beams elastically coupled together at an arbitrary angle," Acta Mechanica Solida Sinica, vol. 25, no. 1, pp. 61-72, 2012.

[17] A. C. Heidebrecht, "Vibration of non-uniform simply-supported beams," Journal of the Engineering Mechanics Division, vol. 93, no. 2, pp. 1-15, 1967. 


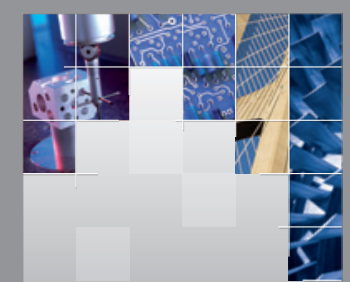

\section{Enfincering}
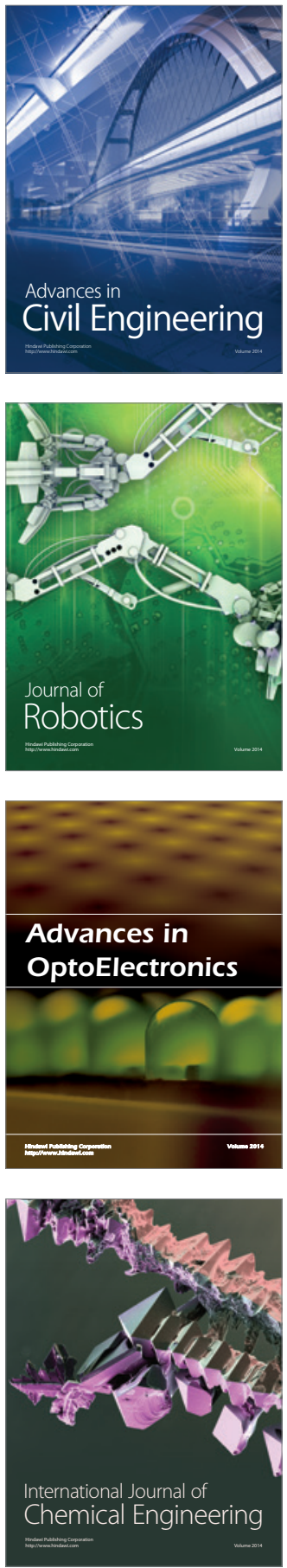

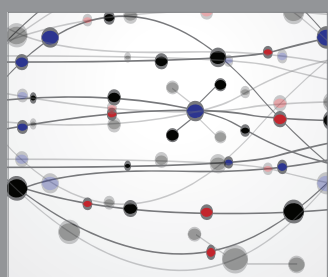

The Scientific World Journal

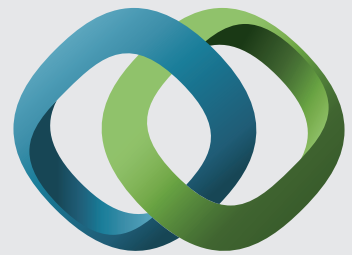

\section{Hindawi}

Submit your manuscripts at

http://www.hindawi.com
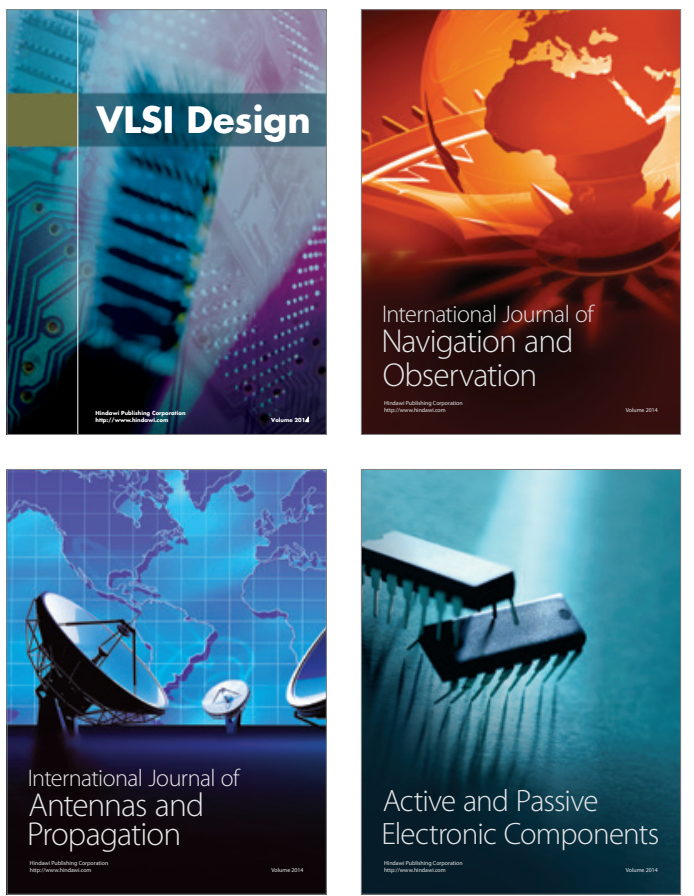
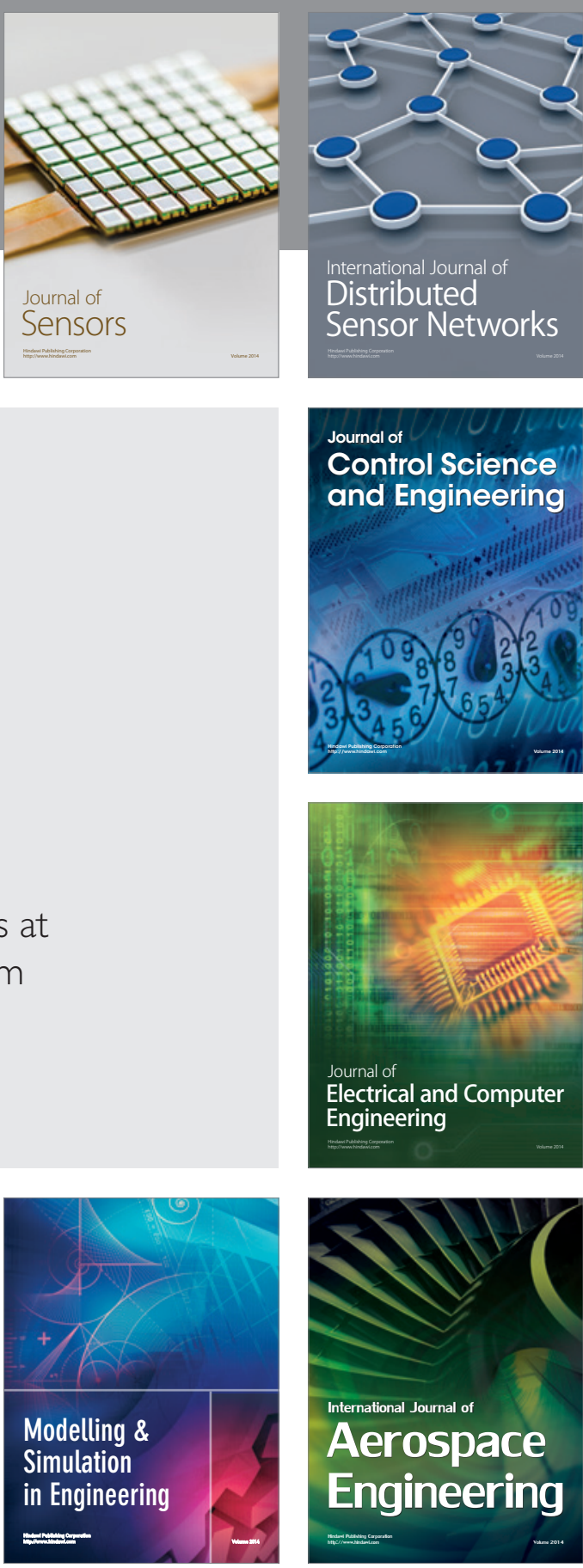

International Journal of

Distributed

Sensor Networks

Journal of

Control Science

and Engineering
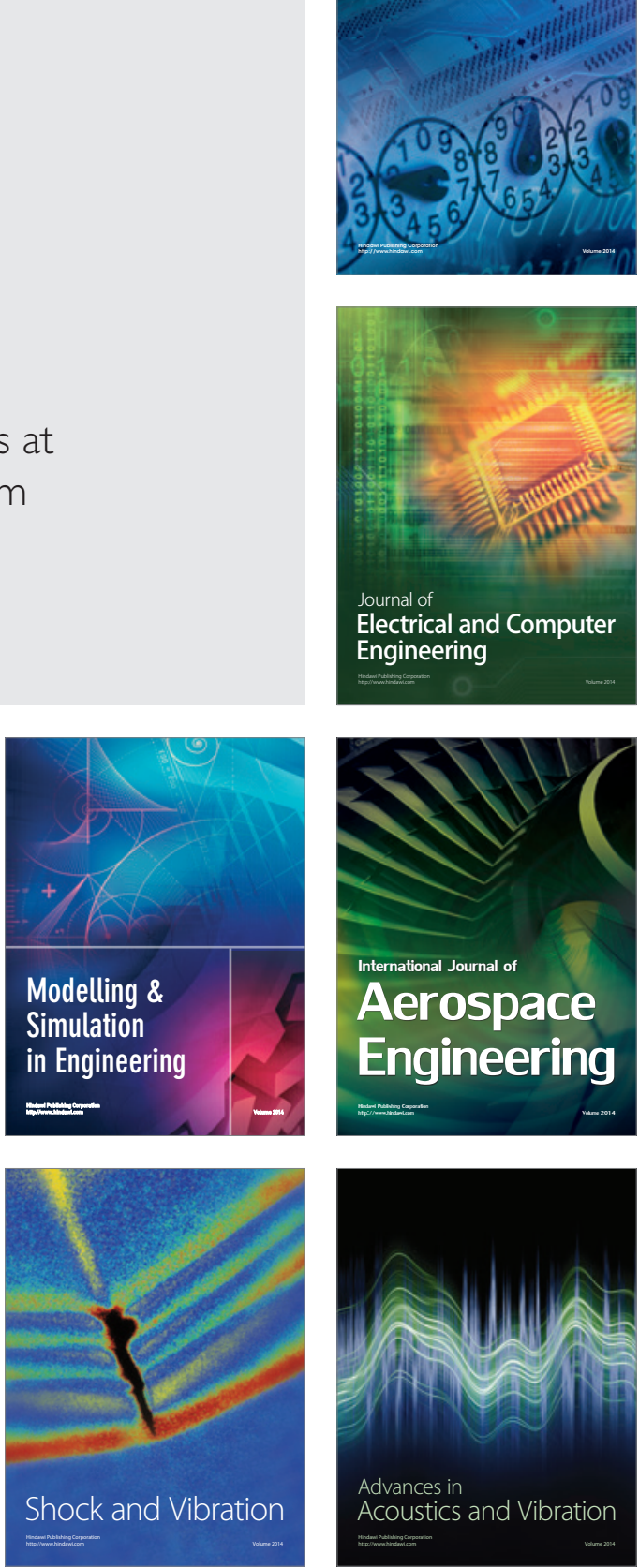